\title{
A blow to the fly - Lucilia cuprina draft genome and transcriptome to support advances in biology and biotechnology
}

Clare A. Anstead ${ }^{\text {a }}$, Philip Batterham ${ }^{\text {b }}$, Pasi K. Korhonen ${ }^{\text {a }}$, Neil D. Young a , Ross S. Hall ${ }^{\mathrm{a}}$, Vernon M. Bowles ${ }^{\mathrm{a}}$, Stephen Richards ${ }^{\mathrm{c}}$, Maxwell J. Scott ${ }^{\mathrm{c}}$, Robin B. Gasser ${ }^{\text {a,* }}$

${ }^{a}$ Faculty of Veterinary and Agricultural Sciences, The University of Melbourne, Parkville, Victoria, Australia

${ }^{\mathrm{b}}$ School of Biosciences, Bio21 Institute, The University of Melbourne, Parkville, Victoria, Australia

${ }^{\mathrm{c}}$ Department of Human and Molecular Genetics, Baylor College of Medicine, Houston, TX 77030 USA

${ }^{\mathrm{d}}$ Department of Entomology, North Carolina State University, Campus Box 7613, Raleigh, NC 27695-7613, USA

* Corresponding author. robinbg@unimelb.edu.au (R. B. Gasser) 


\begin{abstract}
The blow fly, Lucilia cuprina (Wiedemann, 1830) is a parasitic insect of major global economic importance. Maggots of this fly parasitize the skin of animal hosts, feed on excretions and tissues, and cause severe disease (flystrike or myiasis). Although there has been considerable research on $L$. cuprina over the years, little is understood about the molecular biology, biochemistry and genetics of this parasitic fly, as well as its relationship with its hosts and the disease that it causes. This situation might change with the recent report of the draft genome and transcriptome of this blow fly, which has given new and global insights into its biology, interactions with the host animal and aspects of insecticide resistance at the molecular level. This genomic resource will likely enable many fundamental and applied research areas in the future. The present article gives a background on L. cuprina and myiasis, a brief account of past and current treatment, prevention and control approaches, provides a perspective on the impact that the L. cuprina genome should have on future research of this and related parasitic flies, and the design of new and improved interventions for myiasis.
\end{abstract}

Keywords:

Lucilia

Blow fly

Genome

Transcriptome

Molecular biology 


\section{Introduction}

Blow flies, such as Lucilia spp., can parasitize the skin of animals, such as sheep (Arundel and Sutherland, 1988; Stevens, 2003; Smith et al., 2010; Karlsson and Greeff, 2012), causing cutaneous myasis, commonly referred to as flystrike. This disease has been a serious problem in countries with large sheep populations, particularly in parts of Europe, Australia and New Zealand (Hall and Wall, 1995; de Azeredo-Espin and Lessinger, 2006). In Europe, flystrike caused by L. sericata is widespread in sheep farming areas (Heath and Bishop, 1986; Rose and Wall, 2011), with $>80 \%$ of sheep farms affected in the UK (Bisdorff et al., 2006). In Australia and New Zealand, L. cuprina and L. sericata are the predominant sheep blow flies (particularly the former), with $>90 \%$ of myiasis cases being initiated by these species (Watts et al., 1979; Tellam and Bowles, 1997; Plant and Lewis, 2011; Sandeman et al., 2014). In Australasia alone, the annual economic losses due to myiasis linked to reduced wool production and weight loss in sheep is estimated at more than $\$ 320$ million (Heath and Bishop, 1995; Elkington and Mahony, 2007; Urech et al., 2009), including costs associated with blow fly treatment/control and animal morbidity (Arundel and Sutherland, 1988; Heath and Bishop, 1995; Wall, 2012).

In this context, insecticide resistance in L. cuprina is a major problem and has stimulated considerable research efforts to develop alternative interventions for its control (Sandeman et al., 2014). Despite current knowledge of many aspects of this parasitic fly (see Sandeman et al., 2014), very little has been understood about the molecular biology of Lucilia. Major advances in genomic, transcriptomic and bioinformatic techniques (Horner et al., 2010; Mardis, 2013; Koboldt et al., 2013; Cantacessi et al., 2015) are providing exciting opportunities for global studies of the molecular biology and genetics of parasitic blow flies, the interactions that they have with their host(s) and the diseases that they cause. This progress could pave the way for improved intervention methods through the identification and characterization of novel vaccine and insecticide targets, and the development of methods for predicting the molecular mechanisms of insecticide resistance before it evolves, facilitating resistance monitoring and management. In the present article, we (i) review salient aspects of Lucilia biology, particularly for L. cuprina, and the animal health significance of myiasis, (ii) summarize recent progress on the sequencing of the draft genome and transcriptome of L. cuprina, and (iii) emphasize the opportunities that this genome offers for a plethora of future investigations of L. cuprina and for research toward developing new interventions against myiasis.

\section{Background on flystrike and Lucilia}

\subsection{Geographical considerations}

Although flystrike is a problem in all countries with sheep-production, the risk of flystrike is particularly high in Australia due to susceptible breeds of sheep and suitable climatic conditions (Phillips, 2009). Although L. sericata might be Palaearctic in origin, L. cuprina is thought to have originated from the Afrotropical or Oriental regions (Aubertin, 1933; Stevens and Wall, 1996). Using molecular methods, hybrids of $L$. sericata and $L$. cuprina have been shown to occur (Tourle et al., 2009), and a recent study shows that hybrids of these two species can be identified based on their morphology (Williams and Villet, 2014). In addition, two morphologically distinct subspecies have been described: L. cuprina cuprina (Wiedmann, 1830), which is distributed throughout the Neotropical, Oriental and southern Nearctic regions, and L. cuprina dorsalis (Robineau-Desvoidy, 1830), which is distributed throughout the East and sub-Saharan Afrotropical and Australasian regions (Waterhouse and Paramonov, 1950; Spradbery, 1991; Bishop, 1995; Debry et al., 2010).

The sheep blow fly (Lucilia cuprina cuprina) was introduced into Australia in the late 1800s, becoming a major pest species in the $1880 \mathrm{~s}$, with the introduction of the Vermont Merino sheep 
breed (Norris, 1990). This fly established itself in New Zealand in the 1980s via either a single, large or multiple, smaller introductions from Australia (Gleeson et al., 2006). In Australia, $L$. cuprina is a primary fly-strike species, laying eggs on live sheep (Heath and Bishop, 2006), whereas L. sericata is usually restricted to urban habitats and only rarely strikes sheep (Stevens and Wall, 1997). The distribution of L. cuprina relates to the presence of sheep that are susceptible to blow fly strike (Waterhouse, 1947; Foster et al., 1975) and, in Australia, there is evidence for a low dispersal from the breeding site under favorable habitat conditions (Gleeson and Heath, 1997). Research on L. cuprina and flystrike began in the early 1930s by Ian Mackerras at the Council for Scientific and Industrial Research (CSIR) (Mackerras, 1936). Since that time, blow fly strike has been the subject of extensive investigations, and numerous intervention methods have been developed and employed (see Sandeman et al, 2014).

\subsection{Fly biology and disease}

The principal fly involved in flystrike is L. cuprina, with up to $96 \%$ of cases being initiated by this species in various regions of Australia (Watts et al., 1979; Heath and Bishop, 2006). Adult $L$. cuprina females are attracted to odors emanating from their sheep host, particularly those associated with damp fleece or skin soiled by feces and urine (Smith et al., 2010). They find areas of high humidity to lay their eggs, and at each oviposition, a single female L. cuprina can deposit $\sim 200$ eggs in a single egg batch (Whitten et al., 1980). After hatching from eggs (within 8 hours to 3 days when conditions are conducive), the larvae (maggots) proceed through three stages (instars) of development (Tellam and Bowles, 1997). The maggots feed on skin secretions, dermal tissues and blood, using their mouth hooks to abrade the skin (Tellam and Bowles, 1997). The resultant infection is mainly caused by mechanical, chemical and enzymatic effects of the feeding larvae (Sandeman et al., 1990; Heath and Bishop, 2006), which progresses to severe tissue damage, disease ('strike') and, in the most advanced cases, death of the host (Heath, 1994; Morris, 2000; Smith et al., 2010). The third-stage larvae (instars) drop to the ground and burrow into the soil before pupating (Tellam and Bowles, 1997). Newly emerged adults mate, feed on skin and, once mature, females seek-out suitable oviposition sites on the host animal (Watts et al., 1979).

There are several predisposing factors to strike-susceptibility, one of the most important being bacterial infections in damp fleece. The conformation of the sheep body, the sheep's wrinkle score (Turner et al., 1953) and wool characteristics that prevent the skin and fleece from drying completely are all predisposing factors for bacterial dermatitis ('fleece-rot') (Norris et al., 2008); an overgrowth of the natural skin microflora, following a prolonged exposure to moisture, which causes inflammation and ulceration of the skin, and attracts blow flies to lay their eggs (Smith et al., 2010). Insect-microbe interactions (Hilker and Meiners, 2002; Schröder and Hilker, 2008) could be involved in the attraction of L. cuprina to its sheep host. Bacterial interactions with necrophagous flies has been discussed in depth (Thompson et al., 2013), and some studies have shown that particular molecules secreted, for example, by Proteus mirabilis (a gram-negative bacterium) are involved in quorum sensing and also function to attract gravid L. sericata females to corpses for oviposition (Ma et al., 2012; Tomberlin et al., 2012); similar mechanisms or processes might be in place for L. cuprina. Although there are few published studies of the bacteria associated with Lucilia spp., seasonal variation in bacterial communities, and microbe-fly interactions (Banjo et al., 2006; Wei et al., 2014; Singh et al., 2014), initial observations indicate that many of the bacteria associated with Lucilia spp. are acquired from their environment (Singh et al., 2014), that gravid female flies likely select an oviposition site colonized by particular microbes, and that the progeny retain many or most members of the microbial community that they acquire from their initial larval feeding resource (Singh et al., 2014). Bacterial dermatitis also provides moisture for the eggs to hatch successfully and soluble protein for the larvae to feed on after they hatch (Heath, 1994; Morris, 2000; Smith et al., 2010). Bacterial dermatitis and mycotic dermatitis (i.e., dermatophilosis) 
are both predisposing factors for body strike, whereas the main factor for head strike is the presence of horns or a deep wrinkle at the base of the horn (Raadsma, 1993; Karlsson and Greeff, 2012). A predisposing factor for peri-anal (i.e., breech) strike is moist or diarrhoeic faeces and/or an accumulation of faecal matter on breech wool ('dags') (Karlsson and Greeff, 2012). 'Dags' are a significant factor in both summer and winter rainfall regions (Greeff and Karlsson, 2009; Smith et al., 2009a,b). Other contributors to breech strike are wrinkles, breech wool coverage and wool color (Karlsson and Greeff, 2012).

In addition to fleece-rot, dermatophilosis and soiled wool, eye or skin damage caused by grass seeds, hooves with foot-rot, damage or wear around the horns on rams from fighting, and mulesing wounds also attract flies (Cole and Heath, 1999). Although L. cuprina larvae do not usually damage healthy tissue, skin affected with any of these conditions can predispose sheep to infestation. Flystrike and fleece-rot are now generally considered to occur as a disease complex, with the strongest inter-dependence occurring when flystrike occurs on the body of the sheep (Colditz and Tellam, 2000). In Eastern Australia, fleece-rot appears to be the most important factor predisposing sheep to body-strike (Watts, 1979). The identification of predisposing factors and indicators of susceptibility in sheep is central to developing methods for the intervention of flystrike, which, over the years, has included chemical (insecticides), immunological (vaccines), genetic (selective breeding of sheep, and fly transformation), physical (mulesing and crutching) and biological (entomopathogens) methods (reviewed by Sandeman et al., 2014), although none of these methods have provided a sustainable means of control.

\section{Treatment and insecticide resistance problems}

The earliest treatment of flystrike was through the application of chemicals (e.g., arsenic, copper, boron or phenols) to the infected skin (Morley and Johnstone, 1983). During the 1950's, dieldrin and aldrin (both organochlorides) were widely used to prevent flystrike. However, these chemicals were replaced by the organophosphate (OP) insecticide diazinon, when organochlorine resistance linked to a mutation in the $R d l$ gene became widespread in the late 1950's (McKenzie and Batterham, 1998; Phillips, 2009), rendering dieldrin and aldrin ineffective. In addition to diazinon, other OP insecticides, including fenthion-ethyl, coumaphos, chlorfenvinphos, carbophenothion and malathion, were used to prevent flystrike (Tellam and Bowles, 1997). However, surveys in the mid1960s detected resistance in L. cuprina against OP insecticides (Shanahan, 1966; Shanahan and Hart, 1966), and research into the mechanisms of resistance and resistance inheritance began (e.g., Arnold and Whitten, 1976; Hughes and Devonshire, 1982; McKenzie and Whitten, 1982; Terras et al., 1983; Levot, 1995). Although resistance to diazinon due to mutations in the Rop-1 gene emerged in 1965 (Shanahan and Hart, 1966; Newcomb et al., 1997a), and, in spite of widespread resistance in L. cuprina against this organophosphate (Heath, 1994; Levot, 1995), this insecticide was still available for use in Australia until 2007, when its use via jetting or dipping (Holdsworth, 2005) was banned because of concerns of toxicity to operators (Sandeman et al., 2014), but was reintroduced in 2010 (APVMA, 2010). The continued usage of OPs selected for a second site Modifier mutation that ameliorated the fitness costs and asymmetry associated with the Rop-1 mutation (McKenzie and Clarke, 1998).

Over the years, numerous other chemicals have been tested in an attempt to circumvent drug resistance in L. cuprina. Cyromazine, an insect growth regulator, was released in 1979 and worked by inhibiting larval development (Hart et al., 1979), but a limitation of this chemical was that it did not affect adult flies (Hart et al., 1979; Hart et al., 1982). Cyromazine remained effective against flystrike throughout the 1990s; however, low-level resistance against this chemical is quite common in L. cuprina (see Levot, 2012). Diflubenzuron, another insect growth regulator, was developed during the 1980s and interfered with the synthesis of cuticular chitin (Grosscurt, 1978). Although effective at weakening the exoskeleton and subsequently preventing successful molting and egg 
hatch (Levot and Shipp, 1984), high-level resistance was eventually identified in L. cuprina (see Levot and Sales, 2002). In addition, ubiquitous OP resistance in larvae was shown to cause lowlevel cross-resistance to diflubenzuron, a benzoylurea-type insecticide of the benzamide class (Kotze et al., 1997). The introduction of dicyclanil, a chemical with a similar mode of action to cyromazine, followed and had a 10-fold higher efficacy than cyromazine and diflubenzuron, and provided season-long flystrike prevention (Schmid et al., 1999). Dicyclanil continues to be used as a successful preventative compound against flystrike, even partially cyromazine-resistant individuals, which can be controlled using a thorough application of the recommended therapeutic doses of this and cyromazine products (Levot et al., 2014; Sandeman et al., 2014). However, these resistant individuals have been found to be able to initiate flystrike on cyromazine- and dicyclaniltreated sheep more rapidly than on susceptible sheep (Levot et al., 2014). In addition, crossresistance to dicyclanil in cyromazine-resistant mutants of $L$. cuprina has also been detected (Magoc et al., 2005). Ivermectin is another effective compound to treat flystrike (Levot and Sales, 2008), and is recommended as an alternative to cyromazine and dicyclanil in an insecticide-rotation strategy (Levot, 2013); however, ivermectin has poor larvicidal activity for L. cuprina and tends to act primarily as an oviposition deterrent (Sandeman et al., 2014). Some experts argue that it is only a matter of time before resistance against ivermectin and other less commonly used products emerges, because L. cuprina has developed resistance against all existing classes of insecticides, except cyromazine, within less than 10 years of their first release (see Sandeman et al., 2014).

Therefore, insecticides have been heavily relied upon to treat or prevent flystrike, but this reliance is becoming increasingly problematic due to extensive insecticide resistance and residue problems in sheep fleece (Levot, 1995; Shaw, 1997; Sandeman et al., 2014). A number of new insecticides have been proposed, including inhibitors of aminopeptidases (Reed et al., 1999), enzymes involved in egg hatching (Young et al., 1999) and of histone deacetylases (Kotze et al., 2015). Although extensive research has attempted to develop alternative approaches for the protection of sheep against myiasis and/or the control of L. cuprina populations, including biological, immunological and genetic control measures, as well as integrated pest management (reviewed by Sandeman et al., 2014), a sustainable method of control is not yet available.

\section{Immunity and assessment of vaccination}

In order to attempt to circumvent anthelmintic resistance issues, substantial research has focused on trying to develop a vaccine against flystrike (cf. Sandeman et al., 2014). In the late 1970s, research began on the immune and inflammatory responses of sheep against L. cuprina infection (O’Donnell et al., 1980; Elliott et al., 1980; O'Donnell et al., 1981). These studies revealed that the sheep's immune system was able to recognize antigens from blow fly maggots (O'Donnell et al., 1980; Colditz et al., 2006), and further research into the sheep's humoral immune responses to blow fly infection followed (Sandeman et al., 1985; Sandeman et al., 1986; Skelly and Howells, 1987; Eisemann et al., 1990; Bowles et al., 1994; O’Meara et al., 1995). Although there was a limited primary response to blow fly infection, it was established that antibody responses did develop during infection, although, interestingly, previous exposure to flystrike resulted in an increased severity of infection at subsequent exposures (O'Donnell et al., 1980; Sandeman et al., 1986). Specifically, humoral immune responses in sheep were found to larval salivary antigens (Skelly and Howells, 1987) and excretory/secretory (ES) products (Seaton et al., 1992; Tellam et al., 1994). Some studies showed that the infestation of sheep with L. cuprina larvae led to the rapid development of antibodies against larval ES products (Eisemann et al., 1990; Sandeman et al., 1985), and sheep selected for resistance were found to produce a larger inflammatory skin reaction against larval ES proteins than susceptible sheep (Sandeman et al., 1986, O'Meara et al., 1992; MacDiarmid et al., 1995; O'Meara et al., 1995). Molecular differences in exudate compositions from flystrike wounds were also detected between resistant and susceptible sheep, which was 
hypothesized to correlate to inhibition of future infections with L. cuprina larvae (O'Meara et al., 1995). Additional research investigated the sheep's cellular immune response to infection with blow fly larvae was performed (Sandeman et al., 1986; Bowles et al., 1992; Colditz et al., 1994; Elhay et al., 1994; Egan et al., 1996; Nash et al., 1996), which provided some insights into the complexity of cellular events that occur during flystrike in sheep (reviewed by Elkington and Mahony, 2007).

Vaccination experiments began in the early 1980s, employing two general approaches to search for vaccine antigen candidates. The 'natural/conventional antigen' approach employed antigens that are recognized by the sheep's immune system during a natural infection of flystrike, whereas the 'hidden/concealed' antigen approach targeted larval molecules that were not considered to be recognized by the host immune system during infection, and thus did not generate an immune response (Willadsen, 1997; Sandeman et al., 2014). These two approaches allowed for numerous larval antigens (e.g., larval proteases, peritrophic membrane antigens) to be selected and tested (O’Donnell et al., 1981; Johnston et al., 1992; East et al., 1993; Eisemann and Binnington, 1994; Casu et al., 1997; Tellam and Eisemann, 1998; Tellam et al., 2001; Colditz et al., 2002; Tellam et al., 2003; Elkington and Mahony, 2007), and are reviewed extensively by Tellam and Bowles (1997). Several studies assessed recombinant peritrophic membrane proteins (i.e., peritrophin 44, peritrophin 45, and peritrophin 95) as potential immunogens (Casu et al., 1997; Colditz et al., 2002). Another study showed that the inhibition of fly larval growth in vitro was mediated by the ingestion of ovine antibodies produced (mainly) against the peritrophic membrane and larval cuticle (Tellam and Eisemann, 1998). A study by Bowles et al. (1996) showed a significant reduction in both the occurrence of blow fly strike and the size of blow fly larvae in vaccinated sheep compared with controls. Vaccinated sheep displayed both humoral and cellular immune responses against the four partially purified larval antigens utilized for vaccination (Bowles et al., 1996). Although antibody levels correlated with delayed-type hypersensitivity (DTH), neither antibody nor DTH correlated positively with protection. Skin sections from individual sheep immediately following challenge revealed aggregations of $\mathrm{CD}^{+}$Langerhans, $\mathrm{CD}^{+} \mathrm{T}$ helper, and $\gamma \delta$ - $\mathrm{TCR}^{+}$cells in the epidermis in vaccinated sheep, suggesting that an early immune response was responsible for the reduction in the establishment of larvae following vaccination (Bowles et al., 1996).

Other studies have reported a reduction in the immune response of sheep over time, following repeated exposure to blow fly maggots, which led to the conclusion that these larvae were somehow able to evade the sheep immune system (Colditz et al., 2006). Kerlin and East (1992) made similar observations; these authors recorded an apparent immune suppression (reflected in a lack of antibody response) in sheep following co-injection with ES products from blow fly larvae and myoglobin (foreign protein), but not when injected with myoglobin alone. It was proposed that immunosuppressive moieties were present in these ES products, and indeed, in vitro studies showed that such ES products potently inhibited the proliferation of peripheral blood leucocytes stimulated by mitogens. These findings suggested that such moieties promote larval survival by inhibiting the immune response of the live sheep to facilitate the establishment and/or persistence of flystrike. The subsequent isolation of a protein inhibitor of lymphocyte proliferation (Elkington et al., 2009) suggested a mechanism by which larvae could inhibit the immune system. In addition, understanding how some components from larvae suppress the host immune system might also aid in vaccine development (Colditz et al., 2006). Despite major efforts to develop a vaccine against flystrike (cf. Sandeman et al., 2014), no effective vaccine is yet available. It has been demonstrated that ES proteins play critical roles in the immunobiological relationship between L. cuprina larvae and their sheep host. Therefore, a detailed understanding of the roles that these and other molecules play in parasite-host interactions could contribute significantly toward identifying potential vaccine candidates and developing successful subunit vaccines. 


\section{Drosophila melanogaster databases and functional genomic approaches: critical resources to support studies of blow fly biology}

Decoding the genomes and transcriptomes of parasitic flies relies heavily on the understanding of the non-pathogenic vinegar fly Drosophila melanogaster, which has been extensively annotated and curated (FlyBase, www.flybase.org; FlyVar, www.iipl.fudan.edu.cn/FlyVar/; Drysdale et al., 2008; Mohr et al., 2014a; Tang et al., 2015). D. melanogaster has a relatively short life cycle ( 10 days at $25^{\circ} \mathrm{C}$ ), and is easy to culture and maintain in the laboratory (Ashburner et al., 2005). The euchromatic genome of $D$. melanogaster is $120 \mathrm{Mb}$ in size (Adams et al., 2000); although this genome is considerably more compact than that of other flies such as the parasitic tsetse fly, Glossina morsitans (366 Mb), the two species have extensive synteny and orthology (International Glossina Genome Initiative, 2014). Clearly, D. melanogaster has become the model arthropod of choice for comparative and functional genomic studies. Extensive resources, including literature, reagents, fly strains/stocks, online software tools and databases (e.g., FlyBase, FlyMine and FlyRNAi), are now available to underpin comparative analyses and the mining of existing genomic, transcriptomic and proteomic data sets for parasitic flies. In addition to Drosophila databases, annotated insect genomes available through VectorBase (https://www.vectorbase.org/) and the i5k workspace@NAL (https://i5k.nal.usda.gov/) have been important for comparative analyses. Such analyses can be particularly useful for identifying gene functions that may have been gained or lost in/from Drosophila, but not in flies more closely related to L. cuprina. For example, the autoregulatory function of the transformer gene appears to be lost from $D$. melanogaster, but not from L. cuprina, tsetse fly or house fly (Scott et al., 2014a).

The research power of the $D$. melanogaster system has resulted from the isolation of mutants for a high percentage of genes in the genome over the past hundred years (Venken and Bellen, 2014) and the availability of these mutants through stock centers (flystocks.bio.indiana.edu). Mutant analysis has produced a sophisticated understanding of the function of many of genes, and the biological processes that they control in D. melanogaster and in other species as distantly related as humans (Bellen and Yamamoto, 2015). The Drosophila Gene Disruption Project has used a variety of transposable elements (P element, piggyBac and Minos) to create insertion mutants for two thirds of the protein-coding genes in the genome (Bellen et al., 2011). The most recently used element, MiMIC (Minos Mediated Integration Cassette), can generate both loss-of-function mutations and green fluorescent protein (GFP; Chalfie et al., 1994) tags. The latter can be used to display in vivo protein expression patterns, identify protein-binding partners and produce reversible in vivo removal of the protein in a temporal and tissue specific manner (Nargawal-Jaiswal et al., 2015).

Double-stranded RNA interference (RNAi; Fire et al., 1998) revolutionized the study of gene function in metazoan organisms and has elucidated the functions of many genes in D. melanogaster (see Bakal, 2011; Mohr et al., 2014a,b). RNAi relies on the introduction of double-stranded RNA (dsRNA) into the cells of an organism, which induces the degradation of the homologous (target) mRNA (Fire et al., 1998), and can be delivered to D. melanogaster cells or tissues either by injection into pre-cellular blastoderm embryos or as transgenes, but not feeding (as is commonly used in the worm Caenorhabditis elegans and insects that have a systemic RNAi response) (see Perrimon et al., 2010; Wynant et al., 2014). RNAi screens have been used, for example, for the identification of new cellular pathways and essential genes. Although useful, RNAi can produce false-positive and -negative results, like many screening methods. For RNAi, the principal concern are false-positives which can be due to off-target effects (Echeverri et al., 2006; Sigoillot and King, 2011), but progress has been made to enhance the quality of data from such screens through the design of novel bioinformatic and experimental techniques (Mohr et al., 2014b).

The ability to express double-stranded RNA in specific cells has greatly increased the utility of RNAi in D. melanogaster (Dietzl et al., 2007; Yamamoto-Hino and Goto, 2013). Thousands of transgenic lines that express the yeast transcription factor GAL4 have been well characterized 
(Elliott and Brand, 2008). For example, the expression pattern of GAL4 in adult brain and ventral nerve chord has been determined in more than 6000 lines (Jenett et al., 2012). RNAi-mediated knockdown of gene expression is achieved by crossing a GAL4 line with a line that contains a GAL4-responsive promoter (multiple $\mathrm{UAS}_{\mathrm{G}}$ [= upstream activation sequence] binding sites) driving the expression of an inverted repeat construct for the gene of interest. Upon gene transcription, the RNA from the inverted repeat transgene forms a hairpin structure with an extensive region of double-stranded RNA (Dietzl et al., 2007; Yamamoto-Hino and Goto, 2013). Through careful selection of the driver GAL4 lines, it is possible to knockdown gene expression in specific cell types in the fly. An approach to minimize off-target effects (cf. St Johnston, 2013) is to use UASRNAi constructs that target GFP to specifically knock down the activity of viable GFP-tagged genes (e.g., Pastor-Pareja and $\mathrm{Xu}, 2011$; Neumüller et al., 2012). In addition to spatial control, temporal control is achieved through use of a temperature-sensitive version of GAL80, which specifically binds and inhibits GAL4 (McGuire et al., 2003). For example, to examine the role of the general transcription regulator HDAC1 in long-term memory, flies containing UAS-HDAC1, GAL4 and GAL80 transgenes were raised to adulthood at the permissive temperature (Fitzsimons and Scott, 2011). A driver was used that expressed GAL4 in the mushroom bodies in the adult brain, which are essential for long-term memory. When shifted to the non-permissive temperature (3 days before testing), long-term memory was lost. Irrespective of the RNAi technique employed to knock down a gene, it is essential to prove that the observed phenotype is due to silencing of the target. The best way of doing this is to insert a modified copy of the gene that cannot be silenced (e.g., different 3'-UTR) into the genome, to demonstrate that it can rescue the mutant phenotype (St Johnston, 2013).

The D. melanogaster GAL4-UAS system can be exploited to investigate the function of blow fly genes. For example, to examine whether the L. cuprina nicotinic acetylcholine receptor (nAChR) subunit gene $(L c \alpha 6)$ might play a role in resistance to spinosad, a UAS- Lc $\alpha 6$ transgene was introduced into a $D$. melanogaster D $\alpha 6$ loss of function strain that had a high level of resistance to the insecticide (Anstead et al., 2015). When crossed with an appropriate GAL4 driver, expression of $L c \alpha 6$ restored susceptibility to spinosad. Thus, loss of function mutations in the Lca6 gene could lead to evolution of resistance to spinosad in L. cuprina. The GAL4-UAS system could also be used to investigate the odorant binding capacity of the odorant receptors identified in the genome. Hallem and Carlson (2004) developed the $\triangle \mathrm{ab3A}$ antennal neuron mutant that lacks an odor response due to deletion of the endogenous odorant receptor genes. Putative L. cuprina odorant receptors could be expressed in the ab3A neuron using the GAL4-UAS system, and the odorant response of the neuron then determined by standard electrophysiological assays. Lucilia is attracted to some rather putrid odors (Chaudhury et al., 2015), so it is anticipated that some of the odorant receptors will have an odorant binding profile that is markedly different from $D$. melanogaster receptors. Such studies could lead to the development of improved lures for blow flies.

The development of a large number of transgenic GAL4 and UAS lines benefited greatly from the earlier development of an efficient means for making transgenic Drosophila (see Rubin and Spradling, 1982). In addition, transgenesis has been widely used for assessing gene function in $D$. melanogaster (see St Johnston, 2013). D. melanogaster transgenesis typically relies on the features of the $P$-element transposon, which inserts copies of itself into various regions of the genome by a cut-and-paste mechanism (Kaufman and Rio, 1992). This method is efficient, and typically $\leq 50 \%$ of injected flies have progeny that inherit an integrated transgene copy (cf. St Johnston, 2013). With the successful germ-line transformation of Drosophila (Rubin and Spradling, 1982) came the potential for developing transgenic L. cuprina. However, since the $P$-element is not functional outside of the Drosophilidae (Handler et al., 1993), it was necessary to use alternative transposable elements with a broader host range. The genetic transformation of L. cuprina was eventually achieved using a piggyBac vector, but at low efficiency (Heinrich et al., 2002; Scott et al., 2004). Transformation efficiency has been improved by using helper plasmids containing the $h s p 83$ gene 
promoter of L. cuprina to drive expression of the transposase and fluorescent protein marker gene (Concha et al., 2011).

Although a method for transgenesis has been developed, the GAL4-UAS system has not yet been used in L. cuprina. Rather the tTA-tetO two-component regulatory system has been used to control gene expression in transgenic L. cuprina (see Scott, 2014). The advantage of this system is that binding of the tetracycline transactivator (tTA) to tetO can be easily disrupted by the addition of tetracycline to the diet (Gossen and Bujard, 1992; Heinrich and Scott, 2000), which provides a simple off-switch. Recently, transgenic lines of $L$. cuprina were developed that carried a dominant tetracycline repressible female lethal genetic system, with lethality due to overexpression of an auto-regulated tTA gene (Li et al., 2014; Scott et al., 2014a; cf. Sandeman et al., 2014). The tTA transgene contained the sex-specific intron from the previously characterized L. cuprina transformer (tra) gene (Concha and Scott, 2009), which ensured that only the female tTA transcript encoded functional tTA protein. The male-only strains of $L$. cuprina could form the basis for a future genetic control program ( $\mathrm{Li}$ et al., 2014). A disadvantage of the tTA overexpression strains is that females die late in development at the pupal stage. More recently, tetracycline repressible female embryo lethal strains have been developed (Yan and Scott, 2015). The development of these strains built on prior research on the L. sericata pro-apoptotic hid and $r p r$ genes and bnk cellularization gene (Edman et al., 2015). Expression of Lshid or Lsrpr in transgenic Drosophila using the GAL4-UAS system induced widespread apoptosis and organismal death (Edman et al., 2015). Rather than kill L. cuprina females, an attractive alternative is to exploit the sex determination system to cause females to develop as males. For example, induction of expression of Lctra double-stranded RNA could result in the development of a male-only population of flies, which could be sterilized before field release (Concha and Scott, 2009). An alternative to conditional gene expression systems would be to use L. cuprina heat shock gene promoters (Concha et al., 2012).

Recently, the use of the CRISPR/cas9 system to introduce site-specific mutations in the gene of interest has revolutionized our ability to engineer genomes, including D. melanogaster (see Golic, 2013; Kondo, 2014). Cas9 is an RNA-guided nuclease that was first identified as part of a viraldefense system in bacteria (Bhaya et al., 2011; Wiedenheft et al., 2012). In Streptococcus progenies, the tracrRNA is required for cas 9 activity, and the crRNA guides Cas 9 cleavage through specific base-pairing with target DNA (Bhaya et al., 2011; Wiedenheft et al., 2012). Fortunately, the functions of the tracrRNA and crRNA can be replaced with a single guide RNA (sgRNA) in $D$. melanogaster and other fly species (Golic, 2013; Mali et al., 2013). The sgRNA contains $20 \mathrm{nt}$ of homology to the targeted gene. A proto-spacer adjacent motif (PAM), which is typically NGG (sequence), must follow the 20 bp spacer sequence in the target gene. The cells' non-homologous end joining (NHEJ) machinery repairs the cas9-mediated break in the double stranded DNA. Mutations in the targeted gene, which are typically small deletions and insertions, result as a consequence of errors in the repair process. The cas9-induced double-stranded break in the targeted gene can also be repaired via homologous recombination, which is known as homology-directed repair (HDR). By supplying a plasmid template with at least $1 \mathrm{~kb}$ of homology either side of the break point, markers (e.g., GFP) can be precisely inserted into the gene. The frequency of HDR can be increased by inhibiting the NHEJ pathway either by co-injecting doubled-stranded RNA or by using a strain with a mutation in a gene required for NHEJ, such as DNA ligase IV or KU70 (Beumer and Carroll, 2014; Chu et al., 2015); cas9 and sgRNA can be supplied either by injecting pre-cellular embryos with in vitro synthesized RNA, or recombinant protein. Alternatively, transgenic lines that express cas9 in the germline (using vasa or nos gene promoter) and sgRNA from a $U 6$ gene promoter can be used. The latter approach appears to be a particularly efficient means of generating inherited mutations in D. melanogaster (see Kondo and Ueda, 2013; Port et al., 2014). Similar approaches could be taken to make targeted, inherited mutations in the L. cuprina genome. For example, U6 genes and orthologs of vasa and nos have been identified in the $L$. 
cuprina genome (M. J. Scott, unpublished). Alternatively, recombinant cas9 protein or cas9 RNA plus sgRNA could be injected into pre-cellular embryos. Preliminary evidence (Belikoff, Li, Concha, and Scott, unpublished results) suggests that this approach can achieve efficient mutagenesis of red and green fluorescent protein marker genes in transgenic L. cuprina. It could provide a relatively rapid and practical means of screening for mutations that produce a visible phenotype in the adults that develop from injected embryos. For example, loss-of-function mutations in Lctra could cause females to develop male structures, as observed previously in RNAi experiments (Concha and Scott, 2009). In addition to single-gene assays through transgenesis, gene activities in $D$. melanogaster have also been characterized on a genome-wide scale, first using microarrays, and, more recently, employing RNA sequencing (RNA-seq) (e.g., Daines et al., 2011; Malone and Oliver, 2011).

Clearly, tools for the functional analysis and annotation of genes in D. melanogaster have aided the analysis of the genes of this fly in various ways. First, many of these technologies (e.g., RNAi, transgenesis and/or RNA-seq, which were applied to the model fly, D. melanogaster, have then been adapted, with varying degrees of success, to arthropod pests (e.g., Chen et al., 2008; Concha and Scott, 2009; Li et al., 2013; Paim et al., 2013; Yu et al., 2013; Zhang et all., 2013). Second, many of the findings for genes of $D$. melanogaster are likely to be useful to predict functions of orthologs in other flies. In spite of L. cuprina and other parasitic flies having life cycles that are distinct from that of $D$. melanogaster, genomic and transcriptomic evidence suggests relative conservation for numerous gene functions between the vinegar fly and parasitic flies (e.g., International Glossina Genome Initiative, 2014; Anstead et al., 2015). The ability to compare homologous genomic regions and functional data between D. melanogaster and parasitic flies is crucial for exploring the genomes and transcriptomes of the latter insects.

\section{Transcriptomic investigations of $L$. cuprina prior to the availability of a genome}

Molecular studies have been focused on understanding areas including apoptosis (e.g., Rpr; Chen et al., 2004), chemosensation (Leitch et al., 2015), development and thermal adaptation (e.g., $h s p$ genes; Reddy and Tiwari, 2011; Concha et al., 2012), sex-determination (Concha and Scott, 2009; Concha et al., 2010), genetic control (Scott et al., 2011) and insecticide resistance (e.g., Rop-1; Newcomb et al., 1997a) in L. cuprina, and some have investigated the transcription of selected genes in L. cuprina and its congener, L. sericata (e.g., Casu et al., 1994; Garcia et al., 1996; Hannan and Hill, 1997; Hannan and Hill, 2001; McGregor et al., 2001; Tellam et al., 2000, 2003; Tachibana et al., 2005; Blechert et al., 2011; Tarone and Foran, 2011; Pöppel et al., 2014, 2016; Baumann et al., 2015). However, until recently, only two studies (Lee et al., 2011; Sze et al., 2012) had characterized transcriptomes for some developmental stages of these species.

For instance, Lee et al. (2011) undertook expressed sequence tag (EST) sequencing and established a linkage map for L. cuprina. The sequencing and analysis of embryonic and two larval cDNA libraries revealed a great diversity of genes $(>3,280)$, including those related to insecticide resistance (Lee et al., 2011). Homologs of 12 cytochrome P450s, two glutathione S transferases (GSTs) and six esterases were identified in L. cuprina, all of which belong to detoxification gene families (Lee et al., 2011). Expressed sequence tags (ESTs) encoding targeted proteins that had been previously implicated in insecticide resistance (ffrench-Constant et al., 1993; Narahashi, 1996; Raymond-Delpech et al., 2005; Hope et al., 2010) were also identified (Lee et al., 2011). Mitochondria-derived transcripts accounted for $17 \%$ of the entire EST collection, and included 12 protein coding genes and the $16 \mathrm{~S}$ rRNA gene, whereas various ribosomal protein genes ( $R p L 6$, $R p L 7 A, R p L 7, R p L 4$ and $R p S 3 A$ ), elongation factors (efl- $\alpha$, ef2 and ef1- $\gamma$ ), and 18S rRNA were also highly transcribed (Lee et al., 2011). In addition, Lee et al. (2011) was able to assign 41 genes to their respective chromosomes in L. cuprina, the locations of which revealed high conservation of linkage groups, but not of gene order, in comparing the blow fly with D. melanogaster. This study 
also revealed that based on a set of 200 conserved genes, L. cuprina had a lower mean GC content (mean \pm standard deviation; $0.4344 \pm 0.0433$ ) per coding sequence compared with that of $D$. melanogaster $(0.5654 \pm 0.0418)$, and a unique codon usage for 13 of the 18 amino acids encoded by redundant codons (Lee et al., 2011). Overall, this investigation greatly improved the gene inventory for L. cuprina and provided a foundation for expression profiling (Lee et al., 2011). Another study demonstrating differences between $L$. cuprina and D. melanogaster revealed that the L. cuprina TRA protein presents little sequence similarity with the TRA proteins of Drosophila, and is significantly more similar to homologs from tephritid insects (Concha and Scott, 2009). Other features shared by the Calyptratae and the Tephritidae included the genes white eye (Gomulski et al., 2001), glucose-6-phosphate dehydrogenase (Soto-Adames et al., 1994), alcohol dehydrogenase (Brogna et al., 2001), and tra2 (Gomulski et al., 2008).

Subsequently, Sze et al. (2012) characterized the transcriptomes of different stages and tissues (embryonic, larval, pupal and adult; and larval salivary gland) of $L$. sericata. A comparison with data in public databases by homology (BLAST) showed that $47-61 \%$ of the L. sericata transcripts had D. melanogaster orthologs (Sze et al., 2012), and that 39-51\% and 47-60\% had orthologs in Aedes aegypti and Anopheles gambiae, respectively (Sze et al., 2012). Results from nucleotide BLAST searches to 64 known blow fly mRNAs demonstrated that 80-94\% of these genes were found in the L. sericata assemblies (Sze et al., 2012). Multiple families of both Class I and Class II transposable elements were encoded by L. sericata transcripts, as well as the transposable element related domains of RNase $\mathrm{H}$, retroviral aspartyl protease, reverse transcriptase, integrase core domain, dUTPase, transposase, GIY-TIG catalytic domain, DDE superfamily endonuclease, retrotransposon gag protein, Pao retrotransposon peptidase and hAT family dimerization domain were identified (Sze et al., 2012).

Comparative analysis also showed that the transcriptome of L. sericata encoded a Drosophila ortholog of the hybrid male rescue ( $h m r)$ gene (Sze et al., 2012). This locus has been reported as a rapidly evolving gene involved in hybrid incompatibilities (Hutter and Ashburner, 1987; Barbash et al., 2003, 2004), and had been found only in drosophilids prior to the study by Sze et al. (2012). PCR-based analyses provided confirmation of transcript assemblies for nine genes (tra, slow as molasses (slam), doublesex (dsx), head involution defective (hid), serendipity $\alpha$ (sry $\alpha$ ), fruitless (fru), reaper (rpr), bottleneck (bnk) and male-specific lethal-2 (msl-2)) (see Sze et al., 2012). By comparison to Drosophila, Sze et al. (2012) was also able to identify suspected transmembrane protein transporters and vesicle-mediated excretion proteins in the salivary glands of L. sericata, which are necessary for the excretion of molecules involved in antibiotic, anti-biofilm and extraoral digestive activities. In addition, double-stranded RNA transport and refractory responses to viral infections as well as fatty acid and amine metabolism were identified in L. sericata salivary glands, indicating that these functions may be conserved (Sze et al., 2012). Comparisons of adult female and adult male libraries were similar to those of Drosophila; the yolk protein 1 homolog was found only in female L sericata whereas sequences similar to the Male-specific-transcript-35Ba and the Male-specific RNA $98 C b$ were only expressed in male L. sericata (Sze et al., 2012). Numerous sequences similar to genes that matched Drosophila genes expressed in the embryo (giant, bottleneck, sisterless A, ripped pocket, blastoderm-specific gene 25A) and mid-pupation (osiris 8 gene) were also found in the L. sericata embryonic and pupal libraries, respectively (Sze et al., 2012). Other major genes involved in sex determination and differentiation (Sex lethal, tra, transformer 2, dsx and fru), orthologs of pro-apoptotic genes (hid, rpr) and zygotically transcribed genes required for cellularization (sry $\alpha$, bnk, slam) in D. melanogaster were also present in the $L$. sericata transcriptome (Saccone et al., 2002; Sze et al., 2012), although other studies suggest they may play the same role (Concha and Scott, 2009; Edman et al., 2015). Further comparison of the $L$. sericata transcriptome with $D$. melanogaster and two mosquito species using a post-processing algorithm, allowed for further investigation of differential expression among different developmental stages, validation of alternative splicing, and identification of transposable elements 
(Sze and Tarone, 2014). Recently, a study of various stages of L. sericata using RNA-seq revealed unique microRNA (miRNA) profiles in secretions and alimentary tract tissues (Blenkiron et al., 2015). In addition, specific RNA fragments derived from ribosomal RNA and transfer RNAs were present in secretions and particular tissues (Blenkiron et al., 2015). This study showed, for the first time, that the secretions from L. sericata contain RNAs that might have antimicrobial and/or wound healing roles (Blenkiron et al., 2015), which could have important biological and biotechnological implications.

Although these transcriptomic studies provided first, invaluable insights into key groups of genes, there have been issues relating to ambiguous or incomplete assembly, redundancy of transcripts, incomplete annotations, and an inability to quantitatively measure differential transcription and predict alternative splicing. In order to overcome some of these constraints, we aimed at sequencing the nuclear genome of L. cuprina using Illumina technology (Anstead et al., 2015), at a time when this technology was enabling the direct sequencing of many other arthropod genomes as well as transcriptomes. All of the resources available for Drosophila species, particularly D. melanogaster and other drosophilids (Adams et al., 2000; Richards et al., 2005; Clark et al., 2007; Daines et al., 2011; Graveley et al., 2011; Brown et al., 2014; Venken et al., 2015), and other dipterans including An. gambiae, Ae. aegypti, G. morsitans and Musca domestica (see Holt et al., 2002; Nene et al., 2007; Scott et al., 2014b; International Glossina Genome Initiative, 2014), would substantially underpin this effort.

\section{Global insights into L. cuprina through the genome - implications for future molecular discovery and applied research}

Within the framework of the i5k Consortium Initiative (i5k Consortium, 2013), Illumina HiSeq (RNA-seq) sequencing and advanced ALLPATHS-LG assembly methods are being used in a pilot study for the de novo sequencing of genomes and associated transcriptomes of 30 arthropods, with the ultimate goal of decoding 5,000 of these invertebrates to understand their biology. As part of this program and using these technologies, we sequenced and annotated the draft genome of $L$. cuprina (LS strain from Australia; Kotze et al., 1997), and undertook comparative genomic and transcriptomic analyses (Anstead et al., 2015). Here, we review the features and implications of this genome as well as key aspects of L. cuprina development and reproduction, host interactions, immunobiology, and insecticide resistance, as well as putative targets for insecticides and vaccines.

\subsection{Genome features}

The genome of L. cuprina was sequenced at $\sim 100$-fold coverage, producing a final draft assembly of $458 \mathrm{Mb}$ (scaffold N50: 744,413 bp; GC content: 29.3\%) (Anstead et al., 2015). This draft genome is smaller than previous estimates for L. cuprina (see Ullerich and Schöttke, 2006; Picard et al., 2012) and for M. domesica (691 Mb and 1,020 Mb; Picard et al., 2012; Scott et al., 2014b). The estimate of a genome size depends on the method used, with classical methods likely giving an overestimation of size. From the draft genome of L. cuprina, 14,554 protein-coding genes were predicted, and these genes were supported by substantial transcriptomic and proteomic data sets from multiple public databases (Table 1; Anstead et al., 2015). Of these protein-encoding genes, $12,160(83.6 \%)$ could be annotated by comparison to data available for flies including $D$. melanogaster, M. domestica and G. morsitans as well as all accessible protein- and/or conserved protein domain-databases (Anstead et al., 2015). Interestingly, 2,062 genes (14.2\%) were predicted to be unique to L. cuprina, with no homologs detected in any other dipteran for which genome 
sequence data currently available; these genes were thus referred to as orphans (Anstead et al., 2015).

The L. cuprina genome is considerably larger in size than that of D. melanogaster $(180 \mathrm{Mb})$ and G. morsitans $(366 \mathrm{Mb})$ but smaller than that of $M$. domestica $(691 \mathrm{Mb}$; Adams et al., 2000; International Glossina Genome Initiative, 2014; Scott et al., 2014b). In total, 12,160 (83.6\%) genes are shared with at least one other species of dipteran, and 4,106 single-copy orthologs (SCOs) are shared among these four flies (Anstead et al., 2015). In a genome-wide comparison, thousands of SCOs were shared between L. cuprina and D. melanogaster $(\mathrm{n}=3,222)$, L. cuprina and $G$. morsitans $(\mathrm{n}=6,183)$ and L. cuprina and M. domestica $(\mathrm{n}=5,769)$ (Anstead et al., 2015).

\subsection{Fly biology}

To gain new insights into the molecular workings of the blow fly, a comparison of differential transcription between adult male and female, and mixed larval stages of L. cuprina was made (Anstead et al., 2015). Transcripts in male $(\mathrm{n}=138)$ and female $(\mathrm{n}=86)$ adults were highly enriched for gene ontology (GO) terms such as sensory perception of chemical stimuli and defense response (males) and oogenesis and vitelline membrane formation (females) (see Anstead et al., 2015).

The male-enriched transcript set represented genes encoding testis-specific serine kinases, which are proposed to be involved in DNA condensation during post meiotic chromatin remodelling, and a number of proteins linked to antimicrobial and antifungal activities (e.g., phormicin and cecropinC) (see Hultmark et al., 1983; Lambert et al., 1989). Interestingly, the highest transcription detected for any gene in any developmental stage of L. cuprina studied was a male-enriched invertebrate defensin, usually involved in insect immunity (Bulet et al., 2004). This particular phormicin protein had the GO annotations of 'defense response to bacterium' as well as 'innate immune response' (Anstead et al., 2015), and has a homolog in the Northern blow fly (Protophormia terraenovae). Phormicin is responsible for responding to the presence of a bacterium/potential pathogen and triggering defense responses that act to protect the cell of organism (Dimarcq et al., 1990). Like any other organism, flies also respond to invading microorganisms by producing an immune response. Antimicrobial peptides (AMPs) are part of the defense system that insects have developed to fight off pathogenic agents (Bulet and Stöcklin, 2005). Genes coding AMPs in Drosophila have been reviewed in detail (Imler and Bulet, 2005). Another antimicrobial agent, cecropin ( $\mathrm{CecC}$ ), was found highly expressed in the male-enriched transcript set and belongs to the most abundant family of linear AMPs of insect origin (Bulet and Stöcklin, 2005). Expression of cecropin-like peptides has been documented in several other dipteran and lepidopteran insect species (Bulet and Stöcklin, 2005). Male blow flies have a diverse diet, much of which is considered detritus and/or carrion (Mackerras, 1933); therefore, a battery of defense molecules would be needed to combat the bacteria and fungi the fly is inadvertently eating. If these defense molecules could be manipulated or knocked-out, then blow flies could potentially be controlled using bacterial or fungal means.

The male-enriched transcript set also encoded 3 Niemann-Pick type C2 (NPC2) proteins, which are proposed to regulate sterol homeostasis and the biosynthesis of 20-hydroxyecdysone, a steroidal insect-molting hormone (Huang et al., 2007). These proteins appear to play a crucial role in chemical communication, based on evidence for the Japanese carpenter ant (Camponotus japonicus) (Ishida et al., 2014). In addition, 15 sperm-coating protein-like extracellular (SCP/TAPS or CAP) proteins were identified. Many SCP/TAPS proteins are secreted and can function extracellularly in various physiological processes, such as immune responses or fertilization (Niderman et al., 1995; Cantacessi et al., 2009). For instance, Drosophila has 26 SCP/TAPS, some of which are likely involved in male-specific reproductive processes (Kovalick and Griffin, 2005). Clearly, future studies should focus on these interesting genes and assess their functions, as many SCP/TAPS 
proteins are suggested to have important roles in immunomodulation and/or reproduction (Cantacessi et al., 2009), and might represent potential insecticide or vaccine candidates in blow fly.

Encoded within the female-enriched transcript set were molecules inferred to be involved in reproductive processes, such as oogenesis/egg laying and eggshell formation ( Vm26Aa, Vm34Ca, $V m 32 E$, del, yolk protein ( $y p)$ genes), and female sex-determination (stil), all of which have orthologs in Drosophila spp. (Anstead et al., 2015). Although vitelline membrane ( $\mathrm{Vm})$ genes encode proteins of the first eggshell layer, the lipase-derived yolk proteins are needed for vitellogenesis in L. cuprina (Hens et al., 2004). Three complete and one partial yolk protein ( $y p$ ) genes were identified in female L. cuprina (see Scott et al., 2011), in comparison to Drosophila and Glossina, which have three (yp1,yp2, and yp3) and one, respectively (Adams et al., 2000; International Glossina Genome Initiative, 2014). The presence of multiple yp-genes in L. cuprina and Drosophila compared to the single yp-gene found in Glossina may be due to differences in their reproductive biology; oviparous reproduction compared with adenotrophic viviparity in Glossina (Tobe, 1978; Benoit et al., 2015).

Transcripts enriched in mixed-stage $L$. cuprina larvae $(\mathrm{n}=256)$ including those encoding various proteins linked to growth and development (including Ccp84Ab, Lcp 1, Lcp2, Lcp65Ab1 and $E d g 84 A$ ), peritrophin-44 and enzymes (chymotrypsin and cathepsin-D) involved in digestion were abundant (Anstead et al., 2015). Genes encoding cuticle proteins (Lcp1, Lcp2 and Lcp65Ab1) are crucial for cuticle formation (Charles et al., 1997), and an Edg84A ortholog is proposed to govern metamorphosis, being regulated via transcription factors that are homologous to of $D$. melanogaster DHR3 and FTZ-F1 (Murata et al., 1996; Kawasaki et al., 2002; Akagi et al., 2013). Chitin is a major component of the cuticle of arthropods and the effects on L. cuprina larval cuticle by chemical inhibitors of chitin synthesis have been tested in the past (Grosscurt, 1978; Binnington, 1985), resulting in weakening of the larval exoskeleton, thus preventing successful molting and growth, and inhibiting egg hatch. However, due to the development of insecticide resistance to several of these compounds (e.g., diflubenzuron, cyromazine) new technologies targeting chitinbased cuticle development are needed. The fungal chitin synthase competitive inhibitor, nikkomycin Z, has been shown to result in strong concentration-dependent mortality in L. cuprina larvae (Tellam et al., 2000). Interestingly, substantial transcription of the peritrophin-44 gene in larvae compared with adults is consistent with an abundance of this protein in the peritrophic membrane of larvae of L. cuprina and very low amounts in adults (Elvin et al., 1996). Peritrophin44 likely maintains the integrity and porosity of a semi-permeable chitinous matrix of the gut (peritrophic membrane), which protects from microbial invasion and/or facilitates digestive processes, possibly together with cathepsin $\mathrm{D}$ and/or chymotrypsin.

Retinin-like protein genes were also represented amongst larval-enriched transcripts (Anstead et al., 2015). Retinin genes begin to be expressed during the late stage of puparium formation during fly development, and studies suggest that retinin is a cornea-specific protein (Kim et al., 2008). Homologs of five rhodopsin genes ( $R h 1, R h 2, R h 3, R h 5$ and $R h 6$ ) were found in L. cuprina (see Anstead et al., 2015). These data support findings in which four opsin homologs were recovered in the blow fly Calliphora vicina (see Schmitt et al., 2005). In Drosophila, five rhodopsin genes are expressed in the retina, each of which dictates the different functional properties of the photoreceptor cells (e.g., Friedrich et al., 2011). Rh1 and $R h 6$ are LW-sensitive, $R h 3$ and $R h 4$ are UV-sensitive, and $R h 5$ is blue-sensitive (Friedrich et al., 2011). Interestingly, $R h 2$ was not found within the recently published genome of Glossina (International Glossina Genome Initiative, 2014), whereas a homolog to Rh2 in Drosophila was found in Lucilia (Anstead et al., 2015). Both $L$. cuprina and G. morsitans lack a homolog to $R h 4$, but did express the UV-sensitive $R h 3$, which is in contrast to Drosophila which co-express both $R h 3$ and $R h 4$ (Mazzoni et al., 2008). Blow flies are typically the first colonizers of carrion, being drawn by the odor produced (Anderson, 2001); however, besides olfactory stimuli, vision and color also play a role (Wall and Fisher, 2001). Hoping that the success of the screwworm sterile insect technique could be replicated in blow fly, a 
"field female killing" or FFK strain of L. cuprina was developed that carried recessive eye color mutations (Foster et al., 1993; Black et al., 2011). Although the mutation resulted in recessive female lethality and male semi-sterility, successfully suppressing a small L. cuprina population in the initial trial (Foster et al., 1993), this approach was abandoned. However, with some reconfiguration, releasing males carrying vision associated mutations or other female lethal genes may still prove valuable in blow fly control strategies.

\subsection{Molecules predicted to be involved in fly-host interplay}

The complement of ES proteins (encoded in the 'secretome') of L. cuprina likely has critical roles in the digestion of nutrients from the host's skin (termed the 'degradome') as well as the flyhost interplay. The secretome of L. cuprina is predicted to comprise more than 1,000 proteins with a wide spectrum of inferred functions; 234 of them have homologs in multiple public databases (Anstead et al., 2015). Conspicuous were orthologs encoding 11 aspartic proteases (e.g., cathepsin) and 47 serine proteases (e.g., chymotrypsin and trypsin). Also identified were genes encoding peritrophin proteins, mucin-like proteins, hydrolases (e.g., chitinase and lipoprotein lipase) and peptidase inhibitors, such as cuticle-like proteins, serpin B and numerous orphan molecules (Anstead et al., 2015). Many of the secreted peptidases belong to the 'degradome', and their respective inhibitors likely play key roles in the degradation of skin, bacteria, serum/blood and other tissues, and might also be involved in the activation of immune and inflammatory responses (Young et al., 1996; Sandeman et al., 2014). In total, 852 genes were transcribed in larval stages, of which 79 were entirely specific to these stages (Anstead et al., 2015). By comparison to other ecdysozoans, the same number of ES molecules (including peritrophin-44, cuticular proteins and serine peptidases) were predicted to be immunogenic or involved in host interactions (Anstead et al., 2015). Some annotated molecules, such as peritrophins, have also been shown to regulate larval growth and survival (Casu et al., 1997) and induce immunity in sheep against L. cuprina challenge infection (Sandeman et al., 1986). Therefore, overall, these data sets indicate that L. cuprina has a major arsenal of ES proteins, including some orphan molecules that induce and/or modulate immune responses in the host animal. A detailed understanding of the roles of these molecules could contribute to developing a subunit vaccine against flystrike (Elkington and Mahony, 2007).

\subsection{Insecticide resistance genes and the functional analysis of Lca6}

Although there is relatively limited detailed knowledge of the evolution and mechanisms of insecticide resistance in L. cuprina, a number of resistance genes have been identified (McKenzie, 1984; Davies et al., 1992; McKenzie et al., 1992; Smyth et al., 1992; McKenzie and Yen, 1995; Davies et al., 1996; Newcomb et al., 1996; Newcomb et al., 1997a,b; McKenzie and Batterham, 1998; Scott et al., 2000; Chen et al., 2001; Hartley et al., 2006; Perry et al., 2015).

Using genomic data for L. cuprina (see Anstead et al., 2015), five genes linked to particular resistances (Table 2) were annotated. The genes in these long genomic scaffolds were identified and their structures established, providing an important foundation for functional studies of insecticide resistance in L. cuprina and other arthropods. This study (Anstead et al., 2015) also showed, for the first time, the restoration of susceptibility to spinosad in transgenic D. melanogaster expressing the Lc $\alpha 6$ subunit. Previous studies (Perry et al., 2007; Baxter et al., 2010; Puinean et al., 2013) have demonstrated that spinosad-resistance is due to loss-of-function mutations in the gene encoding the nicotinic acetylcholine receptor (nAChR) $\alpha 6$-like subunit (Perry et al., 2007; Baxter et al., 2010; Puinean et al., 2013). This important result demonstrates a conserved functional for this subunit and that $D$. melanogaster serves as a useful model for the analysis of receptor function from other flies. Interestingly, the homologous subunit from $L$. cuprina responds to spinosad in a similar manner to that of D. melanogaster (see Anstead et al., 2015). This finding accords with results from a previous 
study that showed that several $\alpha 6$ subunits from the insects $M$. domestica, Plutella xylostella and Bovicola ovis could also restore spinosad susceptibility (Perry et al., 2015). Overall, the findings of Anstead et al. (2015) indicate that $\alpha 6$-linked resistance evolves in insect pests and emphasizes the need for resistance monitoring. Clearly, the genomic and transcriptomic data sets for L. cuprina provide a significant resource for investigating the evolution and mechanisms of insecticide resistance in parasitic insects.

\subsection{Proposed insecticidal targets}

A total of 92 GTPases were encoded in the L. cuprina genome, including 11 large (heterotrimeric) and 81 small (monomeric) G-proteins representing the Rab, Arf/Sar, Ras, Rho and Ran families (Anstead et al., 2015). GTPases function as control elements for a wide range of cellular processes and complex pathways; GTPases identified in L. cuprina, such as Rho and Ras, might coordinate signal transduction pathways associated with morphogenesis and organogenesis in the fly. For instance, such molecules are involved in the interaction of growing axons with other cells and the extracellular matrices, the dynamics of actin and microtubule cytoskeletal assembly, disassembly and re-organisation, the delivery of lipids and proteins to axons and/or the internalization of membranes or proteins at the leading edge of the growth cone (Hall and Lalli, 2010). In Drosophila, a direct and functional interaction between the monomeric G-proteins Rab5 and Rab4 and the heterotrimeric G-protein Go has been shown to exist, as well as Rab5 being involved in two important signaling pathways (Purvanov et al., 1999). In another study, Magie et al. (1999) demonstrated that when Rhol gene function is disrupted in Drosophila embryos, resultant defects in morphogenetic processes (e.g., cuticle formation) are observed. Dominant small GTPase homologs are Arl1, Arl2, Gaf, Rab6, Ras64B, Rab23, RabX1 and Ras85D, whose D. melanogaster orthologs are essential for larval development (www.flybase.org). These signaling proteins likely play essential roles in embryonic, larval and/or reproductive development and might represent targets for anti-parasite interventions in L. cuprina based on their roles in other organisms such as D. melanogaster (see Sung et al., 2010).

Also of considerable interest in the context of potential insecticide targets are channel, pore and transporter proteins. A total of 136 ion channel proteins were identified in the L. cuprina genome, the majority of which represented the voltage-gated cation channel superfamily, including the potassium and the calcium channel families, and the epithelial and related channel superfamily including acid-sensing ion channels. Channels belonging to the cys-loop superfamily were also found, some of which (e.g., nicotinic acetylcholine receptors) are recognized targets of several insecticides in L. cuprina (see Dederer et al., 2013). In addition, 197 GPCRs were identified in the L. cuprina genome, which included rhodopsins, secretin receptors, and metabotropic glutamate receptors (Anstead et al., 2015). Molecules involved in chemoreception, including a number of gustatory and odorant receptors were conspicuous, with some homologs (e.g., Gr63a) likely involved in the detection of host carbon dioxide (Jones et al., 2007). Transporters $(\mathrm{n}=367)$ were also predicted, including an abundance of proteins of the solute carrier family, major facilitator superfamily and ABC transporters (Anstead et al., 2015), some of which have been shown to relate to insecticide resistance via the active transport of insecticides out of cells (Perry et al., 2011; Dermauw and Van Leeuwen, 2014). Genes (aqp) encoding aquaporins, which likely regulate osmotic pressure in fly cells via rapid and selective transport of water and other small solutes out of and into cells, were also identified (Anstead et al., 2015). At least nine aqp genes were identified in L. cuprina, compared to six, seven, eight and ten in Aedes aegypti, Anopheles gambiae, Drosophila, and Glossina, respectively (International Glossina Genome Initiative, 2014; Benoit et al., 2014a). Recently, the important role of aquaporins, in relation to the physiology of blood-feeding arthropods, has been extensively reviewed (Benoit et al., 2014a,b). These studies highlight four physiological processes in which aquaporins likely play critical roles: hydration of saliva prior or 
during feeding, concentration of the blood meal to facilitate ingestion, provision of water into progeny during oogeny, and the involvement of aquaporins in cold, heat, and dehydration tolerance (Benoit et al., 2014a,b). Pupal L. cuprina are very dependent on soil temperature for their development, and soil temperatures below $13^{\circ} \mathrm{C}$ usually result in the complete arrestment of development, which allows L. cuprina to overwinter (Mackerras, 1933; Tellam and Bowles, 1997). Development of blow fly ovaries is also dependent on temperature (Mackerras, 1933). RNAi mediated gene knockdown of aquaporins has been shown to cause reduced diuresis (Drake et al., 2012; Benoit et al., 2014a,b) and increased survival under dehydrating conditions (Liu et al., 2011; Benoit et al., 2014a,b) in both mosquitoes and Glossina, and impaired heat tolerance in female Glossina (Benoit et al., 2014a,b), highlighting their importance, as well as their potential use as drug targets in other dipterans such as L. cuprina.

\subsection{Prospects for new interventions}

The prediction and prioritization of essential molecules can significantly assist the discovery of new intervention targets. For multicellular organisms, Zhong and Sternberg (2006) successfully integrated data from yeast, fly and nematodes to predict genetic interactions in Caenorhabditis elegans, demonstrating data integration to be an effective strategy to extract biological meaning from existing data sets. Lee et al. (2008) also successfully predicted cellular, developmental and physiological processes in C. elegans using a similar method. As RNAi is not routinely used to assess gene functions on a genome-wide scale in L. cuprina, Anstead et al. (2015) predicted essential single-copy genes of L. cuprina using functional genomic data (lethality) available for orthologs in D. melanogaster. This approach has already yielded credible insecticidal targets and provided insight into the mechanisms of resistance (Olsen and Færgeman, 2012) They elected to focus on single-copy genes, because they do not belong to a gene family, and consequently do not have redundant (related) proteins to replace their function, if they were to be knocked out or deactivated. For L. cuprina, a total of 988 genes with essential D. melanogaster orthologs linked to lethal or semi-lethal phenotypes upon gene silencing were predicted (Anstead et al., 2015). Highest priority was assigned to insecticide or vaccine target candidates encoded by single-copy genes. Druggable genes/proteins using ChEMBL $(n=251)$ were predicted, 79 of which had interacting ligands considered to be 'MedChem-friendly' and satisfying the rule-of-three and rule-of-five (Lipinski, 2004). Conspicuous among the 79 druggable molecules were 4 ion channels and 7 transporters and that might represent primary targets for multiple classes of synthetic or natural compounds, such as isoxazolines (Gassel et al., 2014), avermectins (Albrecht and Sherman, 1987; Bloomquist, 2003), spinosyns (Salgado and Sparks, 2005), synthetic pyrazolines (Silver et al., 2010), ryanoids (Sattelle et al., 2008), arylheterocycles (Bloomquist, 2003), pyrethroids (Dong, 2007), veratrum alkaloids (Ujváry and Casida, 1997), ecdysteroid agonist RH-5849 (Davies et al., 2006) and/or $N$-alkylamides (Gibson et al., 1990). Other candidates included 5 peptidases, 5 growth factor receptors, 7 transcription factors and 19 kinases, some of which have been proposed before (Reed et al., 1999). Interestingly, the homeobox-containing gene, called ladybird late (lbl), encoding a transcription factor with an essential role in the regulation of developmental processes, including cardiogenesis, myogenesis and/or embryonic neurogenesis in D. melanogaster (see Balakirev et al., 2011), was found in L. cuprina (Anstead et al., 2015). The gene sequence of $l b l$ appears to be relatively conserved due to its crucial regulatory functions (Maqbool et al., 2006; Balakirev et al., 2011), and it was proposed that this gene has a role in regulating expression of reporter gene products in the accessory gland of the adult female L. cuprina and thus in reproduction (Anstead et al., 2015). The conservation and essentiality of this transcription factor in dipterans (Maqbool et al., 2006; Attardo et al., 2014) suggest that it might be an interesting focus for functional genomic studies and a novel intervention target in L. cuprina and related flies. 
Several adenosine deaminase-related growth factor $(A D G F)$ genes were also identified in $L$. cuprina, one of which is a SCO of a gene in D. melanogaster (cf. FlyBase), and had high sequence similarity to the $A D G F$ genes in Glossina (Anstead et al., 2015). These genes are of particular interest because they belong to a family of growth factors with high sequence similarity to the enzyme adenosine deaminase, which converts adenosine and deoxyadenosine to inosine and deoxyinosine, respectively. When missing, this enzyme's substrates (i.e., adenosine and deoxyadenosine) accumulate, which is thought to cause severe combined immunodeficiency (SCID) in humans (Dolezal et al., 2005). ADGF-like proteins are found in a wide variety of diverse organisms, including several fly species (e.g., fruit fly, flesh fly, tsetse fly, sand fly; Maier et al., 2001) and a Drosophila model has recently been developed to explore the role of adenosine deaminase (Dolezal et al., 2005). It was found that adenosine and deoxyadenosine concentrations would increase in larvae that lacked the protein ADGF-A, resulting in death due to the disintegration of the fat body, melanomic tumors, and delays and defects in development (Dolezal et al., 2005). When compared to other ADGF-like proteins, three regions of conservation are very apparent; therefore, the conserved structure and sequence suggest that these genes play a similar developmental role in a wide variety of organisms (Maier et al., 2001). In Drosophila, five ADGF genes are involved in larval development (Dolezal et al., 2005). A unique cluster of four $A D G F$ genes has been found in Glossina, whereas sand flies and mosquitoes have a maximum of three $A D G F$ genes (International Glossina Genome Initiative, 2014). However, it has been hypothesized that these genes may play a different role in biting flies compared to their developmental role in flesh flies. Several of these genes are highly expressed in the salivary glands of biting flies (Charlab et al., 2000), and are believed to play a role in the modulation of pain receptors in the host (Charlab et al., 2000; Charlab et al., 2001). Therefore, these genes may have a variety of functions, some of which may have implications for the transmission of vector-borne diseases

Interestingly, in addition to transcripts and genes with annotations, $15 \%$ of the 480 transcripts enriched in L. cuprina larvae or either gender of the adult stages, and $14.2 \%$ of 14,554 genes $(\mathrm{n}=$ 2,062) had no homologs in any other organism for which data were available in public databases at the time (Anstead et al., 2015). Most unannotated transcripts $(n=70)$ were identified in larvae by comparison to male and female adults (Anstead et al., 2015). Moreover, a considerable complement of orphan molecules $(\mathrm{n}=194)$ was in the predicted secretome of L. cuprina (Anstead et al., 2015). Taken together, these findings are similar to those for other dipterans, such as G. morsitans and $M$. domestica, which have similar orphan gene complements (International Glossina Genome Initiative, 2014; Scott et al., 2014b). In addition, in a paper describing the mechanisms and dynamics of orphan gene emergence in insect genomes, similar numbers of orphan genes for individual species were reported in a conservative comparison of 28 insect species (Wissler et al., 2013). The presence of orphan genes emphasizes the uniqueness of the biology of L. cuprina, and encourages detailed studies of the expression and functions of these unique molecules throughout the developmental cycle of the fly. Such unique genes are likely involved in L. cuprina-specific roles relating to host invasion and/or interactions, parasitism, and could represent selective insecticide or vaccine targets.

\section{Conclusions}

The draft genome of $L$. cuprina provides a sound starting point for many future investigations of blow fly biology in a search to find new and innovative interventions against flystrike. The prospects for fundamental and applied research on L. cuprina are almost unlimited. In our opinion, rapid progress can be made in a number of areas, which include genome finishing, comparative genomics/transcriptomics, functional genomics and population genetics.

A first goal should be to complete the genome of L. cuprina, as a solid basis for future research. To do this, we would finish the genome according to the standards set by the National Human Genome Research Institute (NHGRI). Using PacBio (third-generation) sequencing (Schadt et al., 
2010), we would produce 10-12 million (but error-prone) long reads (100-fold coverage) and errorcorrect them using high quality Illumina short-read data. Then, in a stepwise manner, we would integrate long-read sequence data with all previous (short-read) genomic as well as transcriptomic data sets (Anstead et al., 2015) to achieve complete or near-complete gap closure, and then construct the physical map for the fly. Such an effort should lead to a high quality assembly. Recently, a similar approach has been applied to D. melanogaster; this third-generation reassembly of the D. melanogaster genome managed to complete an entire chromosome arm, exceeding the quality that had been achieved using all other sequencing/assembly approaches employed previously (Berlin et al., 2015). The combination of third-generation and diploid assembly techniques should allow the resequencing of L. cuprina to chromosome contiguity. Such sequencing should be able to bridge repetitive regions that cannot be resolved by second-generation Illumina (short read) sequencing, but that might be important for understanding parasite-specific traits of major importance. Clearly, it will also be important to expand to the sequencing of L. cuprina isolates from various geographical regions around the world and undertake comparative genomic and genetic analyses. Originally, Waterhouse and Paramonov (1950) recognized two subspecies, $L$. cuprina cuprina and L. cuprina dorsalis. The genome was assembled from DNA from L. cuprina dorsalis, which is the predominant subspecies in Australia (Norris, 1990). It will be of interest to determine whether a comparative genomics approach can explain some of the observed differences between the subspecies (e.g., coloring). We would also propose to undertake refined orthology and synteny analyses using assembled genomes for other fly species employing recently established tools (cf. Korhonen et al., 2015) and would directly compare our genome (Anstead et al., 2015) with shotgun draft assemblies of genomes available via the i5k project (i5k Consortium, 2013).

A second goal might be to undertake comparative genomic and transcriptomic analyses of $L$. cuprina against a wide range of dipterans. Such comparison should become feasible, because of the proposed sequencing of 5,000 arthropod genomes within the framework of i5k (i5k Consortium, 2013). In August 2014, the database at the Baylor College of Medicine Human Genome Sequencing Centre (https://www.hgsc.bcm.edu/i5k-pilot-project-summary) contains unpublished draft genomic sequences for 35 arthropod species (https://i5k.nal.usda.gov/) (Poelchau et al., 2015). Genomic comparisons between parasitic and non-parasitic flies would enable the identification of genes that undergo positive selection or gene family expansion within particular parasitic lineages and that might relate to parasitism. Comparisons with genomes of other blow flies, such as the New World screwworm, which is an obligate and devastating parasite of animals, will be particularly relevant. In addition, the availability of genomic and transcriptomic sequence data sets for parasitic arthropods should make it possible to now explore the proteome of L. cuprina and predict which of its $>14,500$ protein-coding genes are functional in the larval stages during parasitism but not in larvae of $D$. melanogaster, as well as those that are expressed exclusively in non-parasitic stages of L. cuprina. It may also be possible to identify groups of genes that are co-expressed in the parasitic stages and whose activities promote infection and/or disease. Moreover, it would be interesting to conduct studies of particular tissues of L. cuprina, in order to identify genes that are specifically required for olfactory chemo-attraction to the host animal as well as those of cells in chemosensory neurons involved in the regulation of developmental transitions in the fly. Such studies could be conducted by RNA-seq from small amounts of tissue or single cells (Chintapalli et al., 2013; Shapiro et al., 2013; Stegle et al., 2015).

A third goal could be to explore the genetic structure of $L$. cuprina populations. The ability to study genetic diversity in populations on a genome-wide scale, and to associate variation to genes or proteins linked to important biological characteristics, could have important implications for the control of myiasis. Recently, a practical and cost-effective high throughput genome-wide sequencing-mapping-phylogenetic approach was established to investigate genetic diversity among populations of a parasitic blood fluke (Schistosoma japonicum) of major socioeconomic importance (Young et al., 2015). This approach should be applicable to a wide range of eukaryotic pathogens, 
including flies, and provides a tool to evaluate sequence variation in any exon of any single-copy genes associated with particular phenotypic traits, such as pathogenicity, drug susceptibility/resistance or immunogenicity, and to assess how a particular intervention might relate to, or affect, the phenotype and genotype of L. cuprina. The merit of this approach is in its ability to investigate molecular variation among individuals, at any stage of development, within and among populations. Previous work shows clearly that, for instance, sequence polymorphism in surface proteins of $S$. japonicum recognized as vaccine candidates varies considerably between some populations, suggesting that their antigenicity/immunogenicity in the host might vary considerably. Therefore, in our opinion, it would be prudent to assess sequence conservation for any antigens/immunogens and/or their epitopes prior to pursuing them as possible vaccine molecules. Similar aspects might be considered prior to the development of any new insecticides if/when targets are defined.

A fourth, exciting goal would be to use L. cuprina directly for functional genomic investigations; some technologies utilized for transgenesis, gene inactivation and genomic modification in $D$. melanogaster (see Mohr et al., 2014a,b) could be adapted and applied to L. cuprina. The existence of a usable draft genome (Anstead et al., 2015) is an important step to achieving this goal. Even before the L. cuprina genome was drafted and published, there had been considerable efforts to apply RNAi to silencing Lucilia genes (Li et al., 2013; Concha and Scott, 2009), and we expect the genome to facilitate such efforts to become more effective and practical. In addition, an efficient method was established for the germ-line transformation of L. cuprina (see Heinrich et al., 2002; Concha et al., 2011), which was also applicable to L. sericata. While of major importance for functional studies, the development of such a transgenesis method opens the door to develop strains for the genetic control of Lucilia spp. or for improved "maggot therapy" (Sherman, 2009). In addition to transcription activator-like effector nucleases (TALENs) technology (cf. Kondo et al., 2014), perhaps one of the most exciting developments is the clustered regularly interspaced short palindromic repeats (CRISPR) technology, which allows efficient site-specific mutagenesis of $D$. melanogaster (Bassett and Liu, 2014; Beumer and Carroll, 2014; Xu et al., 2015), and offers a major prospect for modifying or silencing genes in L. cuprina. This prospect could revolutionize genetic and functional genomic analyses of Lucilia and possibly other parasitic flies. With this powerful technology in place, it might be possible to test many of the hypotheses raised in the study of the genome and transcriptome of L. cuprina (see Anstead et al., 2015) and to work toward better methods of flystrike prevention and control. 


\section{Acknowledgements}

Funding from Australian Wool Innovation (AWI; P.B. and R.B.G.) and the Australian Research Council (ARC; to R.B.G.) is gratefully acknowledged. The authors thank staff at the Baylor College of Medicine Human Genome Sequencing Center for the original sequencing and assembly of the $L$. cuprina genome, funded by a grant U54 HG003273 from the National Human Genome Research Institute (NHGRI; to S.R). Support to R.B.G.'s laboratory from YourGene Bioscience and Melbourne Water Corporation as well as the Victorian Life Sciences Computation Initiative (VLSCI; grant no. VR0007) on its Peak Computing Facility at the University of Melbourne is gratefully acknowledged. Support to M.J.S.'s laboratory from the Agriculture Research Service (United States Department of Agriculture), the Panama-United States Commission for the Eradication and Prevention of Screwworm, and the Biotechnology Risk Assessment Grant Program (National Institute of Food and Agriculture, United States Department of Agriculture) is acknowledged. C.A.A. holds an NSERC Postdoctoral Fellowship. N.D.Y. holds an NHMRC Early Career Research Fellowship. P.K.K. is the recipient of a scholarship (STAPA) from the University of Melbourne. Thanks to Dr Joshua Benoit and two anonymous reviewers for their suggestions. 


\section{References}

Adams, M.D., Celniker, S.E., Holt, R.A., Evans, C.A., Gocayne, J.D., Amanatides, P.G., et al., 2000. The genome sequence of Drosophila melanogaster. Science 287, 2185-2195.

Akagi, K., Kageyama, Y., Kayashuma, Y., Takakura, Y., Hirose, S., Ueda, H., 2013. The binding of multiple nuclear receptors to a single regulatory region is important for the proper expression of EDG84A in Drosophila melanogaster. J. Mol. Biol. 425, 71-81.

Albrecht, C.P., Sherman, M., 1987. Lethal and sublethal effects of avermectin B1 on three fruit fly species (Diptera: Tephritidae). J. Econ. Entomol. 80, 344-347.

Anderson GS. Insect succession on carrion and its relationship to determining time of death. In: Byrd JH, Castner JL, editors. Forensic Entomology: the utility of arthropods in legal investigations. Florida: CRC Press LLC; 2001. p. 143-75.

Anstead, C.A.A., Korhonen, P.K., Young, N.D., Hall, R.S., Jex, A.R., Murali, S.C., et al., 2015. Lucilia cuprina genome unlocks parasitic fly biology to underpin future interventions. Nat. Commun. 6, 7344.

APVMA. Suspension of label approvals of selected products containing diazinon. Commonwealth of Australia Gazette 1-5: 2010. p. 13-16.

Arnold, J.T.A., Whitten, M.J., 1976. The genetic basis for organophosphorus resistance in the Australian sheep blowfly, Lucilia cuprina (Wiedemann) (Diptera, Calliphoridae). Bull. Entomol. Res. 66, 561-568.

Arundel JH, Sutherland AK. Blowflies of sheep. In: Arundel JH, Sutherland AK, editors. Animal Health in Australia, Ectoparasitic Diseases of Sheep, Cattle, Goats and Horses. Canberra: Australian Government Publishing Service; 1988. p. 35-60.

Ashburner M, Golic KG, Hawley RS. Drosophila: A Laboratory Handbook. 2nd ed. New York: Cold Spring Harbor Laboratory Press; 2005.

Attardo, G.M., Benoit, J.B., Michalkova, V., Patrick, K.R., Krause, T.B., Aksoy, S., 2014. The homeodomain protein ladybird late regulates synthesis of milk proteins during pregnancy in the tsetse fly (Glossina morsitans). PLoS Negl. Trop. Dis. 8, e2645.

Aubertin, D., 1933. Revision of the genus Lucilia R.-D. (Diptera Calliphoridae). Linn. Soc. J. Zool. 38, 389463.

Bakal, C., 2011. Drosophila RNAi screening in a postgenomic world. Brief. Funct. Genomics 10, 197-205.

Balakirev, E.S., Anisimova, M., Ayala, F.J., 2011. Complex interplay of evolutionary forces in the ladybird homeobox genes of Drosophila melanogaster. PLoS One 6, e22613.

Banjo, A.D., Lawal, O.A., Akintola, O.I., 2006. Bacteria and fungi associated with Lucilia cuprina (sheep blowfly) larvae. Res. J. Agric. Biol. Sci. 2, 358-364.

Barbash, D.A., Awadalla, P., Tarone, A.M., 2004. Functional divergence caused by ancient positive selection of a Drosophila hybrid incompatibility locus. PLoS Biol. 2, 839-848.

Barbash, D.A., Siino, D.F., Tarone, A.M., Roote, J., 2003. A rapidly evolving MYB-related protein causes species isolation in Drosophila. Proc. Natl. Acad. Sci. U.S.A. 100, 5302-5307.Bassett, A.R., Liu, J.L., 2014. CRISPR/Cas9 and genome editing in Drosophila. J. Genet. Genomics 41, 7-19.

Baumann, A., Lehmann, R., Beckert, A., Vilcinskas, A., Franta, Z., 2015. Selection and evaluation of tissue specific reference genes in Lucilia sericata during an immune challenge. PLoS ONE 10, e0135093.

Baxter, S.W., Chen, M., Dawson, A., Zhao, J.Z., Vogel, H., Shelton, A.M., et al., 2010. Mis-spliced transcripts of nicotinic acetylcholine receptor $\alpha 6$ are associated with field evolved spinosad resistance in Plutella xylostella (L.). PLoS Genet. 6, e1000802.

Bellen, H.J., Yamamoto, S., 2015. Morgan's legacy: Fruit flies and the functional annotation of conserved genes. Cell 163, 12-14.

Bellen, H.J., Levis, R.W., He, Y., Carlson, J.W., Evans-Holm, M., Bae, E., et al., 2011. The Drosophila gene disruption project: progress using transposons with distinctive site specificities. Genetics 188, 741-743.

Benoit, J.B., Attardo, G.M., Baumann, A.A., Michalková, V., Aksoy, S., 2015. Adenotrophic viviparity in tsetse flies: potential for population control and as an insect model for lactation. Annu. Rev. Entomol. 60, 19.119.21.

Benoit, J.B., Hansen, I.A., Attardo, G.M., Michalková, V., Mireji, P.O., Bargul, J.L., et al., 2014a. Aquaporins are critical for provision of water during lactation and intrauterine progeny hydration to maintain tsetse fly reproductive success. PLoS Negl. Trop. Dis. 8, e2517.

Benoit, J.B., Hansen, I.A., Szuter, E.M., Drake, L.L., Burnett, D.L., Attardo, G.M., 2014b. Emerging roles of aquaporins in relation to the physiology of blood-feeding arthropods. J. Comp. Physiol. B 184, 811-825. 
Berlin, K., Koren, S., Chin, C.S., Drake, J.P., Landolin, J.M., Phillippy, A.M., 2015. Assembling large genomes with single-molecule sequencing and locality-sensitive hashing. Nat. Biotech. 33, 623-630.

Bhaya, D., Davison, M., Barrangou, R., 2011. CRISPR-Cas systems in bacteria and archaea: versatile small RNAs for adaptive defense and regulation. Annu. Rev. Genet. 45, 273-297.

Beumer, K.J., Carroll, D., 2014. Targeted genome engineering techniques in Drosophila. Methods 68, 29-37.

Binnington, K.C., 1985. Ultrastructural changes in the cuticle of the sheep blowfly, Lucilia, induced by certain insecticides and biological inhibitors. Tissue Cell 17, 131-140.

Bisdorff, B., Wall, R., Milnes, A., 2006. Prevalence and regional distribution of scab, lice and blowfly strike in Great Britain. Vet. Rec. 22, 303-308.

Bishop, D.M., 1995. Subspecies of the Australian green blowfly (Lucilia cuprina) recorded in New Zealand. New Zealand Vet. J. 43, 164-165.

Black IV, W.C., Alphey, L., James, A.A., 2011. Why RIDL is not SIT. Trends Parasitol. 27, 362-370.

Blechert, O., Douglas, D., Baumgartner, S., 2011. Conserved function of the Krüppel gap gene in the blowfly Lucilia sericata, despite anterior shift of expression. Insect Mol. Biol. 20, 257-265.

Blenkiron, C., Tsai, P., Brown, L.A., Tintinger, V., Askelund, K.J., Windsor, J.A., et al., 2015. Characterisation of the small RNAs in the biomedically importatnt green-bottle blowfly Lucilia sericata. PLoS ONE 10, e0122203.

Bloomquist, J.R., 2003. Chloride channels as tools for developing selective insecticides. Arch. Insect Biochem. Physiol. 54, 145-156.

Bowles, V.M., Carnegie, P.R., Sandeman, R.M., 1987. Immunization of sheep against infection with larvae of the blowfly Lucilia cuprina. Int. J. Parasitol. 17, 753-758.

Bowles, V.M., Grey, S.T., Brandon, M.R., 1992. Cellular immune responses in the skin of sheep infected with larvae of Lucilia cuprina, the sheep blowfly. Vet. Parasitol. 44, 151-162.

Bowles, V.M., Meeusen, E.N., Chandler, K., Verhagen, A., Nash, A.D., Brandon, M.R., 1994. The immune response of sheep infected with larvae of the sheep blowfly Lucilia cuprina monitored via efferent lymph. Vet. Immunol. Immunopathol. 40, 341-352.

Bowles, V.M., Meeusen, E.N., Young, A.R., Andrews, A.E., Nash, A.D., Brandon, M.R., 1996. Vaccination of sheep against larvae of the sheep blowfly (Lucilia cuprina). Vaccine 14, 1347-1352.

Brogna, S., Benos, P.V., Gasperi, G., Savakis, C., 2001. The Drosophila alcohol dehydrogenase gene may have evolved independently of the functionally homologous medfly, olive fly, and flesh fly genes. Mol. Biol. Evol. 18, 322-329.

Brown, J.B., Boley, N., Eisman, R., May, G.E., Stoiber, M.H., Duff, M.O., et al., 2014. Diversity and dynamics of the Drosophila transcriptome. Nature 512, 393-399.

Bulet, P., Stöcklin, R., 2005. Insect antimicrobial peptides: structures, properties and gene regulation. Protein Pept. Lett. 12, 3-11.

Bulet, P., Stöcklin, R., Menin, L., 2004. Anti-microbial peptides: from invertebrates to vertebrates. Immunol. Rev. 198, 169-184.Cantacessi, C., Campbell, B.E., Visser, A., Geldhof, P., Nolan, M.J., Nisbet, A.J., et al., 2009. A portrait of the "SCP/TAPS" proteins of eukaryotes - developing a framework for fundamental research and biotechnological outcomes. Biotechnol. Adv. 27, 376-388.

Cantacessi C, Hofmann A, Campbell BE, Gasser RB. Impact of next-generation technologies on exploring socioeconomically important parasites and developing new interventions. In: Cunha MV, Inácio J, editors. Veterinary Infection Biology: Molecular Diagnostics and High-Throughput Strategies. New York: Springer Science+Business Media; 2015. p. 437-74.

Casu, R., Eisemann, C., Pearson, R., Riding, G., East, I., Donaldson, A., et al., 1997. Antibody-mediated inhibition of the growth of larvae from an insect causing cutaneous myiasis in a mammalian host. Proc. Natl. Acad. Sci. U.S.A. 94, 8939-8944.

Casu, R.E., Jarmey, J.M., Elvin, C.M., Eisemann, C.H., 1994. Isolation of a trypsin-like serine protease gene family from the sheep blowfly Lucilia cuprina. Insect Mol. Biol. 3, 159-170.Chalfie, M., Tu, Y., Euskirchen, G., Ward, W.W., Prasher, D.C., 1994. Green fluorescent protein as a marker for gene expression. Science 263, 802-805.

Charlab, R., Rowton, E.D., Ribeiro, J.M., 2000. The salivary adenosine deaminase from the sand fly Lutzomyia longipalpis. Exp. Parasitol. 95, 45-53.

Charlab, R., Valenzuela, J.G., Andersen, J., Ribeiro, J.M.C., 2001. The invertebrate growth factor/CECR1 subfamily of adenosine deaminase proteins. Gene 267, 13-22.

Charles, J. P., Chihara, C., Nejad, S., Riddiford, L. M., 1997. A cluster of cuticle protein genes of Drosophila 
melanogaster at 65A: sequence, structure and evolution. Genetics 147, 1213-1224.

Chaudhury, M.F., Zhu, J.J., Skoda, S.R., 2015. Response of Lucilia sericata (Diptera: Calliphoridae) to screwworm oviposition attractant. J. Med. Entomol. 52, 527-531.

Chen, Z., Newcomb, R., Forbes, E., McKenzie, J., Batterham, P., 2001. The acetylcholinesterase gene and organophosphorus resistance in the Australian sheep blowfly, Lucilia cuprina. Insect Biochem. Mol. Biol. 31, 805-816.

Chen, P., Ho, S.-I., Shi, Z., Abrams, J.M., 2004. Bifunctional killing activity encoded by conserved reaper proteins. Cell Death Differ. 11, 704-713.

Chen, X.G., Mathur, G., James, A.A., 2008. Gene expression studies in mosquitoes. Adv. Genet. 64, 19-50.

Chintapalli, V.R., Wang, J., Herzyk, P., Davies, S.A., Dow, J.A., 2013. Data-mining the FlyAtlas online resource to identify core functional motifs across transporting epithelia. BMC Genomics 14, 518.

Chu, V.T., Weber, T., Wefers, B., Wurst, W., Sander, S., Rajewsky, K., et al., 2015. Increasing the efficiency of homology-directed repair for CRISPR-Cas9-induced precise gene editing in mammalian cells. Nat. Biotechnol. 33, 543-548.

Clark, A.G., Eisen, M.B., Smith, D.R., Bergman, C.M., Oliver, B., Markow, T.A., et al., 2007. Evolution of genes and genomes on the Drosophila phylogeny. Nature 450, 203-218.

Colditz IG, Tellam RL. Host resistance to fleece-rot and fly-strike. In: Cronjé PB, editor. Ruminant Physiology: Digestion, Metabolism, Growth and Reproduction. New York: CAB International; 2000. p. 437-48.

Colditz, I.G., Lax, J., Mortimer, S.I., Clarke, R.A., Beh, K.J., 1994. Cellular inflammatory responses in skin of sheep selected for resistance or susceptibility to fleece rot and fly strike. Parasite Immunol. 16, 289-296.

Colditz, I.G., Mahony, T., Elkington, R., 2006. Using immunology and resistant sheep to beat the fly. Int. J. Sheep Wool Sci. 54, 22-26.

Colditz, I.G., Watson, D.L., Eisemann, C.H., Tellam, R.L., 2002. Production of antibodies to recombinant antigens from Lucilia cuprina following cutaneous immunization of sheep. Vet. Parasitol. 104, 345-350.

Cole, D.J.W., Heath, A.C.G., 1999. Progress towards development and adoption of integrated management systems against flystrike and lice in sheep. Proc. N.Z. Grassland Assoc. 61, 37-42.

Concha, C., Belikoff, E.J., Carey, B.L., Li, F., Schiemann, A.H., Scott, M.J., 2011. Efficient germ-line transformation of the economically important pest species Lucilia cuprina and Lucilia sericata (Diptera, Calliphoridae). Insect Biochem. Mol. Biol. 41, 70-75.

Concha, C., Edman, R.M., Belikoff, E.J., Schiemann, A.H., Carey, B., Scott, M.J., 2012. Organization and expression of the Australian sheep blowfly (Lucilia cuprina) hsp23, hsp24, hsp70 and hsp 83 genes. Insect Mol. Biol. 21, 169-180.

Concha, C., Li, F., Scott, M.J., 2010. Conservation and sex-specific splicing of the doublesex gene in the economically important pest species Lucilia cuprina. J. Genetics 89, 279-285.

Concha, C., Scott, M.J., 2009. Sexual development in Lucilia cuprina (Diptera, Calliphoridae) is controlled by the transformer gene. Genetics 182, 785-798.Daines, B., Wang, H., Wang, L., Li, Y., Han, Y., Emmert, D., et al., 2011. The Drosophila melanogaster transcriptome by paired-end RNA sequencing. Genome Res. 21, 315-324.

Davies, A.G., Batterham, P., McKenzie, J.A., 1992. Fatal association between dieldrin-resistant and susceptible Australian sheep blowflies, Lucilia cuprina. Proc. Biol. Sci. 247, 125-129.

Davies, A.G., Game, A.Y., Chen, Z., Williams, T.J., Goodall, S., Yen, J.L., et al., 1996. Scalloped wings is the Lucilia cuprina Notch homologue and a candidate for the modifier of fitness and asymmetry of diazinon resistance. Genetics 143, 1321-1337.

Davies, L., Williams, D.R., Aguiar-Santana, I.A., Pedersen, J., Turner, P.C., Rees, H.H., 2006. Expression and down-regulation of cytochrome P450 genes of the CYP4 family by ecdysteroid agonists in Spodoptera littoralis and Drosophila melanogaster. Insect Biochem. Mol. Biol. 36, 801-807.

de Azeredo-Espin, A.M.L., Lessinger, A.C., 2006. Genetic approaches for studying myiasis-causing flies: molecular markers and mitochondrial genomics. Genetica 126, 111-131.

Debry, R., Timm, A.E., Dahlem, G.A., Stamper, T., 2010. mtDNA-based identification of Lucilia cuprina (Wiedemann) and Lucilia sericata (Meigen) (Diptera: Calliphoridae) in the continental United States. Forensic Sci. Int. 202, 102-109.

Dederer, H., Berger, M., Meyer, T., Werr, M., Ilg, T., 2013. Structure-activity relationships of acetylcholine derivatives with Lucilia cuprina nicotinic acetylcholine receptor $\alpha 1$ and $\alpha 2$ subunits in chicken $\beta 2$ subunit hybrid receptors in comparison with chicken nicotinic acetylcholine receptor $\alpha 4 / \beta 2$. Insect Mol. 
Biol. 22, 183-198.

Dermauw, W., Van Leeuwen, T., 2014. The ABC gene family in arthropods: comparative genomics and role in insecticide transport and resistance. Insect Biochem. Mol. Biol. 45, 89-110.

Dietzl, G., Chen, D., Schnorrer, F., Su, K.C., Barinova, Y., Fellner, M., et al., 2007. A genome-wide transgenic RNAi library for conditional gene inactivation in Drosophila. Nature 448, 151-156.

Dimarcq, J.-L., Zachary, D., Hoffmann, J.A., Hoffmann D., Reichhart, J.-M., 1990. Insect immunity: expression of the two major inducible antibacterial peptides, defensin and diptericin, in Phormia terranovae. EMBO J. 9, 2507-2515.

Dolezal, T., Dolezelova, E., Zurovec, M., Bryant, P.J., 2004. A role for adenosine deaminase in Drosophila larval development. PLoS Biol. 3, e201.

Dong, K., 2007. Insect sodium channels and insecticide resistance. Invert. Neurosci. 7, 17-30.

Drake, L.L., Price, D.P., Aguirre, S.E., Hansen, I.A., 2012. RNAi-mediated gene knockdown and in vivo diuresis assay in adult female Aedes aegypti mosquitoes. J. Vis. Exp. 65, e3479.

Drysdale, R., FlyBase Consortium, 2008. FlyBase: a database for the Drosophila research community. Methods Mol. Biol. 420, 45-59.

East, I.J., Fitzgerald, C.J., Pearson, R.D., Donaldson, R.A., Vuocolo, T., Cadogan, L.C., et al., 1993. Lucilia cuprina: inhibition of larval growth induced by immunization of host sheep with extracts of larval peritrophic membrane. Int. J. Parasitol. 23, 221-229.

Edman, R.M., Linger, R.J., Belikoff, E.J., Li, F., Sze, S.-H., Tarone, A.M., et al., 2015. Functional characterization of calliphorid cell death genes and cellularization gene promoters for controlling gene expression and cell viability in early embryos. Insect Mol. Biol. 24, 58-70.

Egan, P.J., Kimpton, W., Seow, H.F., Bowles, V.M., Brandon, M.R., Nash, A.D., 1996. Inflammation-induced changes in the phenotype and cytokine profile of cells migrating through skin and afferent lymph. Immunol. $89,539-546$.

Eisemann, C.H., Binnington, K.C., 1994. The peritrophic membrane: its formation, structure, chemical composition and permeability in relation to vaccination against ectoparasitic arthropods. Int. J. Parasitol. 24, $15-26$.

Eisemann, C.H., Johnston, L.A., Broadmeadow, M., O’Sullivan, B.M., Donaldson, R.A., Pearson, R.D., et al., 1990. Acquired resistance of sheep to larvae of Lucilia cuprina, assessed in vivo and in vitro. Int. J. Parasitol. 20, 299-305.

Elhay, M.J., Hanrahan, C.F., Bowles, V.M., Seow, H.F., Andrews, A.E., Nash, A.D., 1994. Cytokine mRNA expression in skin in response to ectoparasite infection. Parasite Immunol. 16, 451-461.

Elkington, R.A., Humphries, M., Commins, M., Maugeri, N., Tierney, T., Mahony, T.J., 2009. A Lucilia cuprina excretory-secretory protein inhibits the early phase of lymphocyte activation and subsequent proliferation. Parasite Immunol. 31, 750-765.

Elkington, R.A., Mahony, T.J., 2007. A blowfly strike vaccine requires an understanding of host-pathogen interactions. Vaccine 25, 5133-5145.

Elliott, M., Pattie, W.A., Dobson, C., 1980. The immune response of sheep to larvae of Lucilia cuprina. Proc. Aust. Soc. Anim. Prod. 13, 500.

Elliott, D.A., Brand, A.H., 2008. The GAL4 system: a versatile system for the expression of genes. Methods Mol. Biol. 420, 79-95.

Elvin, C.M., Vuocolo, T., Pearson, R.D., East, I.J., Riding, G.A., Eisemann, C.H., et al., 1996. Characterization of a major peritrophic membrane protein, peritrophin-44, from the larvae of Lucilia cuprina: cDNA and deduced amino acid sequences. J. Biol. Chem. 271, 8925-8935.

Echeverri, C.J., Beachy, P.A., Baum, B., Boutros, M., Buchholz, F., Chandra, S.K., et al., 2006. Minimizing the risk of reporting false positives in large-scale RNAi screens. Nat. Methods 3, 777-779.

ffrench-Constant, R.H., Steichen, J.C., Rocheleau, T.A., Aronstein, K., Roush, R.T., 1993. A single-amino acid substitution in a $\gamma$-aminobutyric acid subtype A receptor locus is associated with cyclodiene insecticide resistance in Drosophila populations. Proc. Natl. Acad. Sci. U.S.A. 90, 1957-1961.

Fire, A., Xu S., Montgomery, M.K., Kostas, S.A., Driver, S.E., Mello, C.C., 1998. Potent and specific genetic interference by double-stranded RNA in Caenorhabditis elegans. Nature 391, 806-811.

Fitzsimons, H.L., Scott, M.J., 2011. Genetic modulation of Rpd3 expression impairs long-term courtship memory in Drosophila. PLoS One 6, e29171.

Foster, G.G., Kitching, R.L., Vogt, W.G., Whitten, M.J., 1975. Sheep blowfly and its control in the pastoral ecosystem of Australia. Proc. Ecol. Soc. Aus. 9, 213-229. 
Foster GG, Weller GL, James WJ, Paschalidis KM, McKenzie LJ. Advances in sheep blowfly genetic control in Australia. In: Proceedings: Management of insect pests: nuclear and related molecular and genetic techniques. Vienna: International Atomic Energy Agency (IAEA) Symposium; 1993. p. 299-312.

Friedrich, M., Wood, E.J., Wu, M., 2011. Developmental evolution of the insect retina: insights from standardized numbering of homologous photoreceptors. J. Exp. Zool. (Mol. Dev. Evol.) 316, 484-499.

Garcia, R.L., Perkins, H.D., Howells, A.J., 1996. The structure, sequence and developmental pattern of expression of the white gene in the blowfly Lucilia cuprina. Insect Mol. Biol. 5, 251-260.

Gassel, M., Wolf, C., Noack, S., Williams, H., Ilg, T., 2014. The novel isoxazoline ectoparasiticide fluralaner: selective inhibition of arthropod $\gamma$-aminobutyric acid- and L-glutamate-gated chloride channels and insecticidal/acaricidal activity. Insect Biochem. Mol. Biol. 45, 111-124.

Gibson, A.J., Osborne, M.P., Ross, H.F., Sawicki, R.M., 1990. An electrophysiological study of susceptible (Cooper) and resistant ( $k d r$; super-kdr) strains of the adult housefly (Musca domestica L.) using an isolated mesothoracic leg preparation. Pestic. Sci. 30, 379-396.

Gleeson DM, Harman H, Armstrong T. Genetics of invasive species in New Zealand. In: Allen RB, Lees WG, editors. Biological Invasions in New Zealand. Berlin: Springer-Verlag; 2006. p. 103-18.

Gleeson, D.M., Heath, A.C.G., 1997. The population biology of the Australian sheep blowfly, Lucilia cuprina, in New Zealand. N. Z. J. Agric. Res. 40, 529-535.

Golic, K.G., 2013. RNA-guided nucleases: a new era for engineering the genomes of model and nonmodel organisms. Genetics 195, 303-308.

Gomulski, L.M., Dimopoulos, G., Xi, Z., Soares, M.B., Bonaldo, M.F., Malacrida, A.R., et al., 2008. Gene discovery in an invasive tephritid model pest species, the Mediterranean fruit fly, Ceratitis capitata. BMC Genomics 9, 243.

Gomulski, L.M., Pitts, R.J., Costa, S., Saccone, G., Torti, C., Polito, L.C., et al., 2001. Genomic organization and characterization of the white locus of the Mediterranean fruitfly, Ceratitis capitata. Genetics 157, 12451255.Gossen, M., Bujard, H., 1992. Tight control of gene expression in mammalian cells by tetracyclineresponsive promoters. Proc. Natl. Acad. Sci. U.S.A. 89, 5547-5551.

Graveley, B.R., Brooks, A.N., Carlson, J.W., Duff, M.O., Landolin, J.M., Yang, L., et al., 2011. The developmental transcriptome of Drosophila melanogaster. Nature 471, 473-479.

Greeff, J.C., Karlsson, L.J.E., 2009. Opportunities to breed for breech strike resistance in Merino sheep in a Mediterranean environment. Proc. Assoc. Advmt. Anim. Breed. Genet. 18, 272-278.

Grosscurt, A.C., 1978. Diflubenzuron: some aspects of its ovicidal and larvicidal mode of action and an evaluation of its practical possibilities. Pestic. Sci. 9, 373-386.

Hall, A., Lalli, G., 2010. Rho and Ras GTPases in axon growth, guidance, and branching. Cold Spring Harb. Perspect. Biol. 2, a001818.

Hall, M., Wall, R., 1995. Myiasis of humans and domestic animals. Adv. Parasitol. 35, 257-334.

Hallem, E.A., Carlson, J.R., 2004. The odor coding system of Drosophila. Trends Genet. 20, 453-459.

Handler, A.M., Gomez, S.P., O'Brochta, D.A., 1993. A functional analysis of the $P$-element gene-transfer vector in insects. Arch. Insect Biochem. Physiol. 22, 373-384.

Hannan, G.N., Hill, R.J., 1997. Cloning and characterization of LcEcR: a functional ecdysone receptor from the sheep blowfly Lucilia cuprina. Insect Biochem. Mol. Biol. 27, 479-488.

Hannan, G.N., Hill, R.J., 2001. Lcusp, an ultraspiracle gene from the sheep blowfly, Lucilia cuprina: cDNA cloning, developmental expression of RNA and confirmation of function. Insect Biochem. Mol. Biol. 31, 771-781.

Hart, R.J., Cavey, W.A., Ryan, K.J., Moore, B., Strong, M.B., 1979. Technical details of a new sheep blowfly insecticide. Wool Tech. Sheep Bree. 27, 23-27.

Hart, R.J., Cavey, W.A., Ryan, K.J., Strong, M.B., Moore, B., Thomas, P.L., et al., 1982. CGA-72662 - A new sheep blowfly insecticide. Aust. Vet. J. 59, 104-109.

Hartley, C.J., Newcomb, R.D., Russell, R.J., Yong, C.G., Stevens, J.R., Yeates, D.K., et al., 2006. Amplification of DNA from preserved specimens shows blowflies were preadapted for the rapid evolution of insecticide resistance. Proc. Natl. Acad. Sci. U.S.A. 103, 8757-8762.

Heath, A. C. G., 1994. Ectoparasites of livestock in New Zealand. New Zeal. J. Zool. 21, 23-38.

Heath, A.C.G., Bishop, D.M., 1986. The distribution and importance of blowfly strike in New Zealand. New Zeal. J. Zool. 13, 419.

Heath, A.C.G., Bishop, D.M., 1995. Flystrike in New Zealand. Surveillance 22, 11-13. 
Heath, A.C.G., Bishop, D.M., 2006. Flystrike in New Zealand: an overview based on a 16-year study, following the introduction and dispersal of the Australian sheep blowfly, Lucilia cuprina Wiedemann (Diptera: Calliphoridae). Vet. Parasitol. 137, 333-344.

Heinrich, J.C., Li, X., Henry, R.A., Haack, N., Stringfellow, L., Heath, A.C., et al., 2002. Germ-line transformation of the Australian sheep blowfly Lucilia cuprina. Insect Mol. Biol. 11, 1-10.

Heinrich, J.C., Scott, M.J., 2000. A repressible female-specific lethal genetic system for making transgenic insect strains suitable for a sterile-release program. Proc. Natl. Acad. Sci. U.S.A. 97, 8229-8232.

Hens, K., Macours, N., Claeys, I., Francis, C., Huybrechts, R., 2004. Cloning and expression of the yolk protein of the tsetse fly Glossina morsitans morsitans. Insect Biochem. Mol. Biol. 34, 1281-1287.

Hilker, M., Meiners, T., 2002. Chemoecology of insect eggs and egg deposition. Blackwell Publishing, Berlin.

Holdsworth, P.A., 2005. Ectoparasiticide use in contemporary Australian livestock production. Avcare Ltd. Report, ISBN 0-9750845-1-8, Canberra, ACT, Australia.

Holt, R.A., Subramanian, G.M., Halpern, A., Sutton, G.G., Charlab, R., Nusskern, D.R., et al., 2002. The genome sequence of the malaria mosquito Anopheles gambiae. Science 298, 129-149.

Hope, M., Menzies, M., Kemp, D., 2010. Identification of a dieldrin resistance-associated mutation in Rhipicephalus (Boophilus) microplus (Acari: Ixodidae). J. Econ. Entomol. 103, 1355-1359.

Horner, D.S., Pavesi, G., Castrignanò, T., D’Onorio De Meo, P., Liuni, S., Sammeth, M., et al., 2010. Bioinformatics approaches for genomics and post genomics applications of next-generation sequencing. Brief. Bioinform. 11, 181-197.

Huang, X., Warren, J.T., Buchanan, J., Gilbert, L.I., Scott, M.P., 2007. Drosophila Niemann-Pick type C-2 genes control sterol homeostasis and steroid biosynthesis: a model of human neurodegenerative disease. Development 134, 3733-3742.

Hughes, P.B., Devonshire, A.L., 1982. The biochemical basis of resistance to organophosphorus insecticides in the sheep blowfly, Lucilia cuprina. Pestic. Biochem. Physiol. 18, 289-297.

Hultmark, D., Engström, A., Andersson, K., Steiner, H., Bennich, H., Boman, H.G., 1983. Insect immunity. Attacins, a family of antibacterial proteins from Hyalophora cecropia. EMBO J. 2, 571-576.

Hutter, P., Ashburner, M., 1987. Genetic rescue of inviable hybrids between Drosophila melanogaster and its sibling species. Nature 327, 331-333.

i5k Consortium, 2013. The i5k initiative: advancing arthropod genomics for knowledge, human health, agriculture, and the environment. J. Hered. 104, 595-600.

Imler, J.L., Bulet, P., 2005. Antimicrobial peptides in Drosophila: structures, activities and gene regulation. Chem. Immunol. Allergy 86, 1-21.

International Glossina Genome Initiative, 2014. Genome sequence of the tsetse fly (Glossina morsitans): vector of African Trypanosomiasis. Science 25, 380-386.

Ishida, Y., Tsuchiya, W., Fujii, T., Fujimoto, Z., Miyazawa, M., Ishibashi, J., et al., 2014. Niemann-Pick type $\mathrm{C} 2$ protein mediating chemical communication in the worker ant. Proc. Natl. Acad. Sci. U.S.A 111, 38473852.

Jenett, A., Rubin, G.M., Ngo, T.T., Shepherd, D., Murphy, C., Dionne, H., et al., 2012. A GAL4-driver line resource for Drosophila neurobiology. Cell Rep. 2, 991-1001.

Johnston, L.A.Y., Eisemann, C.H., Donaldson, R.A., Pearson, R.D., Vuocolo, T., 1992. Retarded growth of Lucilia cuprina larvae on sheep and their sera following production of an immune response. Int. J. Parasitol. 22, 187-193.

Jones, W.D., Cayirlioglu, P., Kadow, I.G., Vosshall, L.B., 2007. Two chemosensory receptors together mediate carbon dioxide detection in Drosophila. Nature 445, 86-90.

Karlsson, L.J.E., Greeff, J.C., 2012. Genetic aspects of sheep parasitic diseases. Vet. Parasitol. 189, 104-112.

Kaufman, P.D., Rio, D.C., 1992. P element transposition in vitro proceeds by a cut-and-paste mechanism and uses GTP as a cofactor. Cell 69, 27-39.

Kawasaki, H., Hirose, S., Ueda, H., 2002. $\beta$ FTZ-F1 dependent and independent activation of Edg78E, a pupal cuticle gene, during the early metamorphic period in Drosophila melanogaster. Dev. Growth Differ. 44, 419-425.

Kerlin, R.L., East, I.J., 1992. Potent immunosuppression by secretory/excretory products of larvae from the sheep blowfly Lucilia cuprina. Parasite Immunol. 14, 595-604.

Kim, E., Choi, Y., Lee, S., Seo, Y., Yoon, J., Baek, K., 2008. Characterization of the Drosophila melanogaster retinin gene encoding a cornea-specific protein. Insect Mol. Biol. 17, 537-543.

Koboldt, D.C., Steinberg, K.M., Larson, D.E., Wilson, R.K., Mardis, E.R., 2013. The next-generation 
sequencing revolution and its impact on genomics. Cell 155, 27-38.

Kondo, S., 2014. New horizons in genome engineering of Drosophila melanogaster. Genes Genet. Syst. 89, 3-8.

Kondo, T., Sakuma, T., Wada, H., Akimoto-Kato, A., Yamamoto, T., Hayashi, S., 2014. TALEN-induced gene knock out in Drosophila. Dev. Growth Differ. 56, 86-91.

Kondo, S., Ueda, R., 2013. Highly improved gene targeting by germline-specific Cas9 expression in Drosophila. Genetics 195, 715-721.

Korhonen, P.K., Pozio, E., La Rosa, G., Chang, B., Koehler, A.V., Jex, A.R., et al., 2015. Phylogenomic and biogeographic reconstruction of the Trichinella complex. Nat. Commun. 7, 10513.

Kotze, A.C., Sales, N., Barchia, I.M., 1997. Diflubenzuron tolerance associated with monooxygenase activity in field strain larvae of the Australian sheep blowfly (Diptera: Calliphoridae). J. Econ. Entomol. 90, 15-20.

Kotze, A.C., Hines, B.M., Bagnall, N.H., Anstead, C.A., Gupta, P., Reid, R.C., et al., 2015. Histone deacetylase enzymes as drug targets for the control of the sheep blowfly, Lucilia cuprina. Int. J. Parasitol. Drug Drug Resist. 5, 201-208.

Kovalick, G.E., Griffin, D.L., 2005. Characterization of the SCP/TAPS gene family in Drosophila melanogaster. Insect Biochem. Mol. Biol. 35, 825-835.

Lambert, J., Keppi, E., Dimarcq, J.L., Wicker, C., Reichhart, J.M., Dunbar, B., et al., 1989. Insect immunity: isolation from immune blood of the dipteran Phormia terranovae of two insect antibacterial peptides with sequence homology to rabbit lung macrophage bactericidal peptides. Proc. Natl. Acad. Sci. U.S.A. 86, 262266.

Lee, I., Lehner, B., Crombie, C., Wong, W., Fraser, A.G., Marcotte, E.M., 2008. A single gene network accurately predicts phenotypic effects of gene perturbation in Caenorhabditis elegans. Nat. Genet. 40, 181188.

Lee, S.F., Chen, Z., McGrath, A., Good, R.T., Batterham, P., 2011. Identification, analysis, and linkage mapping of expressed sequence tags from the Australian sheep blowfly. BMC Genomics 12, 406.

Leitch, O., Papanicolaou, A., Lennard, C., Kirkbride, K.P., Anderson, A., 2015. Chemosensory genes identified in the antennal transcriptome of the blowfly Calliphora stygia. BMC Genomics 16, 255.

Levot, G.W., 1995. Resistance and the control of sheep ectoparsites. Int. J. Parasitol. 25, 1355-1362.

Levot, G.W., 2012. Cyromazine resistance detected in Australian sheep blowfly. Aust. Vet. J. 90, 433-443.

Levot, G.W., 2013. Response to laboratory selection with cyromazine and susceptibility to alternative insecticides in sheep blowfly larvae from the New South Wales Monaro. Aust. Vet. J. 91, 61-64.

Levot, G.W., Langfield, B.J., Aiken, D.J., 2014. Survival advantage of cyromazine-resistant sheep blowfly larvae on dicyclanil- and cyromazine-treated Merinos. Aust. Vet. J. 92, 421-426.

Levot, G.W., Sales, N., 2002. New high level resistance to diflubenzuron detected in the Australian sheep blowfly, Lucilia cuprina (Wiedemann)(Diptera: Calliphoridae). Gen. Appl. Entomol. 31, 43-45.

Levot, G.W., Sales, N., 2008. In-vitro effectiveness of ivermectin and spinosad flystrike treatments against larvae of the Australian sheep blowfly Lucilia cuprina (Wiedemann) (Diptera: Calliphoridae). Aust. J. Entomol. 47, 365-369.

Levot, G.W., Shipp, E., 1984. Reduction in offspring survival of Lucilia cuprina (Wiedemann) following consumption of insect development inhibitors. J. Aust. Ent. Soc. 23, 85-89.

Li, F., Vensko, S.P. 2nd, Belikoff, E.J., Scott, M.J., 2013. Conservation and sex-specific splicing of the transformer gene in the calliphorids Cochliomyia hominivorax, Cochliomyia macellaria and Lucilia sericata. PLoS One 8, e56303.

Li, F., Wantuch, H.A., Linger, R.J., Belikoff, E.J., Scott, M.J., 2014. Transgenic sexing system for genetic control of the Australian sheep blowfly Lucilia cuprina. Insect Biochem. Mol. Biol. 51, 80-88.

Lipinski, C.A., 2004. Lead- and drug-like compounds: the rule-of-five revolution. Drug Discov. Today Technol. $1,337-341$.

Liu, K., Tsujimoto, H., Cha, S.J., Agre, P., Rasgon, J.L., 2011. Aquaporin water channel AgAQP1 in the malaria vector mosquito Anopheles gambiae during blood feeding and humidity adaptation. Proc. Nat. Acad. Sci. U.S.A 108, 6062-6066.

Ma, Q., Fonseca, A., Liu, W., Fields, A.T., Pimsler, M.L., Spindola, A.F., et al., 2012. Proteus mirabilis interkingdom swarming signals attract blow flies. ISME J. 6, 1356-1366.

MacDiarmid, A., Clarke, R., McClure, S.J., Bowen, F.R., Burrell, D.H., 1995. Use of a monoclonal antibody to ovine IgE for fly strike studies in sheep. Int. J. Parasitol. 25, 1505-1507.

Mackerras, I.M., 1936. The Sheep Blowfly Problem in Australia. Pamph. Coun. Sci. Indust. Res. no. 66, CSIR, Australia. 
Mackerras, M.J., 1933. Observations on the life-histories, nutritional requirements and fecundity of blowflies. Bull. Entomol. Res. 24, 353-362.

Magie, C.R., Meyer, M.R., Gorsuch, M.S., Parkhurst, S.M., 1999. Mutations in the Rho1 small GTPase disrupt morphogenesis and segmentation during early Drosophila development. Development 126, 5353-5364.

Magoc, L., Yen, J.L., Hill-Williams, A., McKenzie, J.A., Batterham, P., Daborn, P.J., 2005. Cross-resistance to dicyclanil in cyromazine-resistant mutants of Drosophila melanogaster and Lucilia cuprina. Pestic. Biochem. Physiol. 81, 129-135.

Maier, S.A., Podemski, L., Graham, S.W., McDermid, H.E., Locke, J., 2001. Characterization of the adenosine deaminase-related growth factor (ADGF) gene family in Drosophila. Gene 280, 27-36.

Malone, J.H., Oliver, B., 2011. Microarrays, deep sequencing and the true measure of the transcriptome. BMC Biol. 9, 34.

Mali, P., Esvelt, K.M., Church, G.M., 2013. Cas9 as a versatile tool for engineering biology. Nat. Methods 10, 957-963.

Mardis, E.R., 2013. Next-generation sequencing platforms. Annu. Rev. Anal. Chem. (Palo. Alto. Calif.) 6, 287303.

Maqbool, T., Soler, C., Jagla, T., Daczewska, M., Lodha, N., Palliyil, S., et al., 2006. Shaping leg muscles in Drosophila: role of ladybird, a conserved regulator of appendicular myogenesis. PLoS One 1, e122.

Mazzoni, E.O., Celik, A., Wernet, M.F., Vasiliauskas, D., Johnston, R.J., Cook, T.A., et al., 2008. Iroquois complex genes induce co-expression of rhodopsins in Drosophila. PLoS Biol. 6, e97.

McGuire, S.E., Le, P.T., Osborn, A.J., Matsumoto, K., Davis, R.L., 2003. Spatiotemporal rescue of memory dysfunction in Drosophila. Science 302, 1765-1768.

McGregor, A.P., Shaw, P.J., Dover, G.A., 2001. Sequence and expression of the hunchback gene in Lucilia sericata: a comparison with other Dipterans. Dev. Genes Evol. 211, 315-318.

McKenzie, J.A., 1984. Dieldrin and diazinon resistance in populations of the Australian sheep blowfly, Lucilia cuprina, from sheep-grazing areas and rubbish tips. Aust. J. Biol. Sci. 37, 367-374.

McKenzie, J.A., Batterham, P., 1998. Predicting insecticide resistance: mutagenesis, selection and response. Philos. Trans. R. Soc. Lond. B Biol. Sci. 353, 1729-1734.

McKenzie, J.A., Clarke, G.M., 1998. Diazinon resistance, fluctuating asymmetry and fitness in the Australian sheep blowfly, Lucilia cuprina. Genetics 120, 213-220.

McKenzie, J.A., Parker, A.G., Yen, J.L., 1992. Polygenic and single gene responses to selection for resistance to diazinon in Lucilia cuprina. Genetics 130, 613-620.

McKenzie, J.A., Whitten, M.J., 1982. Selection for insecticide resistance in the Australian sheep blowfly, Lucilia cuprina. Experientia 38, 84-85.

McKenzie, J.A., Yen, J.L., 1995. Genotype, environment and the asymmetry phenotype. Dieldrin-resistance in Lucilia cuprina (the Australian sheep blowfly). Heredity 75, 181-187.Mohr, S.E., Hu, Y., Kim, K., Housden, B.E., Perrimon, N., 2014a. Resources for functional genomics studies in Drosophila melanogaster. Genetics 197, 1-18.

Mohr, S.E., Smith, J.A., Shamu, C.E., Neumüller, R.A., Perrimon, N., 2014b. RNAi screening comes of age: improved techniques and complementary approaches. Nat. Rev. Mol. Cell Biol. 15, 591-600.

Morley FHW, Johnstone IL. Mules operation: a review of development and adoption. In: Raadsma HW, editor. Sheep Blowfly and Flystrike in Sheep. Sydney: Second National Symposium; 1983.

Morris, M.C., 2000. Ethical issues associated with sheep fly strike research, prevention and control. J. Agric. Environ. Ethics 13, 205-217.

Murata, T., Kageyama, Y., Hirose, S., Ueda, H., 1996. Regulation of the EDG84A gene by FTZ-F1 during metamorphosis in Drosophila melanogaster. Mol. Cell. Biol. 16, 6509-6515.

Nagarkar-Jaiswal, S., Lee, P.T., Campbell, M.E., Chen, K., Anguiano-Zarate, S., Gutierrez, M.C., et al., 2015. A library of MiMICs allows tagging of genes and reversible, spatial and temporal knockdown of proteins in Drosophila. eLife 4, e05338.

Narahashi, T., 1996. Neuronal ion channels as the target sites of insecticides. Pharmacol. Toxicol. 79, 1-14.

Nash, A.D., Egan, P.J., Kimpton, W., Elhay, M.J., Bowles, V.M., 1996. Local cell traffic and cytokine production associated with ectoparasite infection. Vet. Immunol. Immunopathol. 54, 269-279.

Nene, V., Wortman, J.R., Lawson, D., Haas, B., Kodira, C., Tu, Z.J., et al., 2007. Genome sequence of Aedes aegypti, a major arbovirus vector. Science 316, 1718-1723.

Newcomb, R.D., Campbell, P.M., Ollis, D.L., Cheah, E., Russell, R.J., Oakeshott, J.G., 1997a. A single amino acid substitution converts a carboxylesterase to an organophosphorus hydrolase and confers insecticide 
resistance on a blowfly. Proc. Natl. Acad. Sci. U.S.A. 94, 7464-7468.

Newcomb, R.D., Campbell, P.M., Russell, R.J., Oakeshott, J.G., 1997b. cDNA cloning, baculovirus-expression and kinetic properties of the esterase, E3, involved in organophosphorus resistance in Lucilia cuprina. Insect Biochem. Mol. Biol. 27, 15-25.

Newcomb, R.D., East, P.D., Russell, R.J., Oakeshott, J.G., 1996. Isolation of alpha cluster esterase genes associated with organophosphate resistance in Lucilia cuprina. Insect Mol. Biol. 5, 211-216.

Neumüller, R.A., Wirtz-Peitz, F., Lee, S., Kwon, Y., Buckner, M., Hoskins, R.A., et al., 2012. Stringent analysis of gene function and protein-protein interactions using fluorescently tagged genes. Genetics 190, 931-940.

Niderman, T., Genetet, I., Bruyère, T., Gees, R., Stintzi, A., Legrand, M., et al., 1995. Pathogenesis-related PR1 proteins are antifungal. Plant Physiol. 108, 17-27.

Norris, K.R., 1990. Evidence for the multiple exotic origin of Australian populations of the sheep blowfly, Lucilia cuprina (Wiedemann) (Diptera: Calliphoridae). Aust. J. Zool. 38, 635-648.

Norris, B.J., Colditz, I.G., Dixon, T.J., 2008. Fleece rot and dermatophilosis in sheep. Vet. Microbiol. 128, $217-$ 230.

O’Donnell, I.J., Green, A.P.E., Connell, B.J.A., Hopkins, P.S., 1980. Immunoglobulin G antibodies to the antigens of Lucilia cuprina in the sera of fly-struck sheep. Aust. J. Biol. Sci. 33, 27-34.

O’Donnell, I.J., Green, A.P.E., Connell, B.J.A., Hopkins, P.S., 1981. Immunization of sheep with larval antigens of Lucilia cuprina. Aust. J. Biol. Sci. 34, 411-417.

Olsen, L.C.B., Færgeman, N.J., 2012. Chemical genomics and emerging DNA technologies in the identification of drug mechanisms and drug targets. Curr. Top. Med. Chem. 12, 1331-1345.

O’Meara, T.J., Nesa, M., Raadsma, H.W., Saville, D.G., Sandeman, R.M., 1992. Variation in skin inflammatory responses between sheep bred for resistance or susceptibility to fleece rot and blowfly strike. Res. Vet. Sci. $52,205-210$.

O’Meara, T.J., Nesa, M., Seaton, D.S., Sandeman, R.M., 1995. A comparison of inflammatory exudates released from myiasis wounds on sheep bred for resistance or susceptibility to Lucilia cuprina. Vet. Parasitol. 56, 207-223.

Paim, R.M., Araujo, R.N., Lehane, M.J., Gontijo, N.F., Pereira, M.H., 2013. Application of RNA interference in triatomine (Hemiptera: Reduviidae) studies. Insect Sci. 20, 40-52.

Pastor-Pareja, J.C., Xu, T., 2011. Shaping cells and organs in Drosophila by opposing roles of fat body-secreted Collagen IV and perlecan. Dev. Cell 21, 245-256.

Phillips, C.J.C., 2009. A review of mulesing and other methods to control flystrike (cutaneous myiasis) in sheep. Anim. Welfare 18, 113-121.

Plant, J.W., Lewis, C.J., 2011. Treatment and control of ectoparasites in sheep. Vet. Clin. North Am. Food Anim. Pract. 27, 203-212.

Perrimon, N., Ni, J.Q., Perkins, L., 2010. In vivo RNAi: today and tomorrow. Cold Spring Harb. Perspect. Biol. 2, a003640.

Perry, T., Batterham, P., Daborn, P.J., 2011. The biology of insecticidal activity and resistance. Insect Biochem. Mol. Biol. 41, 411-422.

Perry, T., McKenzie, J.A., Batterham, P., 2007. A Dalpha6 knockout strain of Drosophila melanogaster confers a high level of resistance to spinosad. Insect Biochem. Mol. Biol. 37, 184-188.

Perry, T., Somers, J., Yang, Y.T., Batterham, P., 2015. Expression of insect $\alpha$ 6-like nicotinic acetylcholine receptors in Drosophila melanogaster highlights a high level of conservation of the receptor:spinosyn interaction. Insect Biochem. Mol. Biol. 64, 106-115.

Picard, C.J., Johnston, J.S., Tarone, A.M., 2012. Genome sizes of forensically relevant Diptera. J. Med. Entomol. 49, 192-197.

Poelchau, M., Childers, C., Moore, G., Tsavatapalli, V., Evans, J., Lee, C.Y., et al., 2015. The i5k workspace@NAL - enabling genomic data access, visualization and curation of arthropod genomes. Nucl. Acids Res. 43, D714-D719.

Pöppel, A.-K., Kahl, M., Baumann, A., Wiesner, J., Gökçen, A., Beckert, A., et al., 2016. A Jonah-like chymotrypsin from the therapeutic maggot Lucilia sericata plays a role in wound debridement and coagulation. Insect Biochem. Mol. Biol. 70, 138-147.

Pöppel, A.-K., Koch, A., Kogel, K.-H., Vogel, H., Kollewe, C., Wiesner, J., et al., 2014. Lucimycin, an antifungal peptide from the therapeutic maggot of the common green bottle fly Lucilia sericata. Biol. Chem. 395, 649-656.

Port, F., Chen, H.M., Lee, T., Bullock, S.L., 2014. Optimized CRISPR/Cas tools for efficient germline and 
somatic genome engineering in Drosophila. Proc. Natl. Acad. Sci. U.S.A. 111, E2967- E2976.

Puinean, A.M., Lansdell, S.J., Collins, T., Bielza, P., Millar, N.S., 2013. A nicotinic acetylcholine receptor transmembrane point mutation (G275E) associated with resistance to spinosad in Frankliniella occidentalis. J. Neurochem. 124, 590-601.

Purvanov, V., Koval, A., Katanaev, V.L., 2010. A direct and functional interaction between Go and Rab5 during G protein-coupled receptor signaling. Sci. Signal. 3, ra65.

Raadsma, H.W., 1993. Fleece rot and bodystrike in Merino sheep. VI. Experimental evaluation of some physical fleece and body characteristics as indirect selection criteria for fleece rot. Aust. J. Agric. Res. 44, 915-931.

Raymond-Delpech, V., Matsuda, K., Sattelle, B.M., Rauh, J.J., Sattelle, D.B., 2005. Ion channels: molecular targets of neuroactive insecticides. Invert. Neurosci. 5, 119-133.

Reed, B.J., Chandler, D.S., Sandeman, R.M., 1999. Aminopeptidases as potential targets for the control of the Australian sheep blowfly, Lucilia cuprina. Int. J. Parasitol. 29, 839-850.

Reddy, P.V.J., Tiwari, P.K., 2011. Genomic structure and sequence analysis of Lucilia cuprina HSP90 gene. Cell. Mol. Biol. 57, 106-115.

Richards, S., Liu, Y., Bettencourt, B.R., Hradecky, P., Letovsky, S., Nielsen, R., et al., 2005. Comparative genome sequencing of Drosophila pseudoobscura: chromosomal, gene, and cis-element evolution. Genome Res. 15, 1-18.

Rose, H., Wall, R., 2011. Modelling the impact of climate change on spatial patterns of disease risk: sheep blowfly strike by Lucilia sericata in Great Britain. Int. J. Parasitol. 41, 739-746.

Rubin, G.M., Spradling, A.C., 1982. Genetic transformation of Drosophila with transposable element vectors. Science 218, 348-353.

Saccone, G., Pane, A., Polito, L.C., 2002. Sex determination in flies, fruitflies and butterflies. Genetica 116, 1523.

Salgado VL, Sparks TC. The spinosyns: chemistry, biochemistry, mode of action, and resistance. In: Gilbert LI, Latrou K, Gill SS, editors. Comprehensive Molecular Insect Science. Oxford: Elsevier; 2005. p.137-73.

Sandeman, R.M., Bowles, V.M., Stacey, I.A., Carnegie, P.R., 1986. Acquired resistance in sheep to infection with larvae of the blowfly Lucilia cuprina. Int. J. Parasitol. 16, 69-75.

Sandeman, R.M., Dowse, C.A., Carnegie, P.R., 1985. Initial characterization of the sheep immune response to infections of Lucilia cuprina. Int. J. Parasitol. 15, 181-185.

Sandeman, R.M., Feehan, J.P., Chandler, R.A., Bowles, V.M., 1990. Tryptic and chymotryptic proteases released by the larvae of the blowfly, Lucilia cuprina. Int. J. Parasitol. 20, 1019-1023.

Sandeman, R.M., Levot, G.W., Heath, A.C.G., James, P.J., Greeff, J.C., Scott, M.J., et al., 2014. Control of the sheep blowfly in Australia and New Zealand - are we there yet? Int. J. Parasitol. 44, 879-891.

Sattelle, D.B., Cordova, D., Cheek, T.R., 2008. Insect ryanodine receptors: molecular targets for novel pest control chemicals. Invert. Neurosci. 8, 107-119.

Schadt, E.E., Turner, S., Kasarskis, A., 2010. A window into third-generation sequencing. Hum. Mol. Genet. 19, R227-R240.

Schmid, H.R., van Tulder, G., Junquera, P., 1999. Field efficacy of the insect growth regulator dicyclanil for flystrike prevention on lambs. Vet. Parasitol. 86, 147-151.

Schmitt, A., Vogt, A., Friedmann, K., Paulsen, R., Huber, A., 2005. Rhodopsin patterning in central photoreceptor cells of the blowfly Calliphora vicina: cloning and characterization of Calliphora rhodopsins Rh3, Rh5 and Rh6. J. Exp. Biol. 208, 1247-1256.

Schröder, R., Hilker, M., 2008. The relevance of background odor in resource location by insects: a behavioral approach. BioSci. 58, 308-316.

Scott, M., Diwell, K., McKenzie, J.A., 2000. Dieldrin resistance in Lucilia cuprina (the Australian sheep blowfly): chance, selection and response. Heredity 84, 599-604.

Scott, M.J., 2014. Development and evaluation of male-only strains of the Australian sheep blowfly, Lucilia cuprina. BMC Genetics 15, S3.

Scott, M.J., Atapattu, A., Schiemann, A.H., Concha, C., Henry, R., Carey, B.L., et al., 2011. Organisation and expression of a cluster of yolk protein genes in the Australian sheep blowfly, Lucilia cuprina. Genetica 139, 63-70.

Scott, M.J., Heinrich, J.C., Li, X., 2004. Progress towards the development of a transgenic strain of the Australian sheep blowfly (Lucilia cuprina) suitable for a male-only sterile release program. Insect Biochem. Mol. Biol. 34, 185-192.

Scott, M.J., Pimsler, M.L., Tarone, A.M., 2014a. Sex determination mechanisms in the Calliphoridae (blow 
flies). Sex. Dev. 8, 29-37.

Scott, J.G., Warren, W.C., Beukeboom, L.W., Bopp, D., Clark, A.G., Giers, S.D., et al., 2014b. Genome of the house fly, Musca domestica L., a global vector of diseases with adaptations to a septic environment. Genome Biol. 15, 466.

Seaton, D.S., O’Meara, T.J., Chandler, R.A., Sandeman, R.M., 1992. The sheep antibody response to repeated infection with Lucilia cuprina. Int. J. Parasitol. 22, 1169-1174.

Shanahan, G.J., 1966. Organophosphorus tolerance in sheep blowflies. NSW Dept. Ag. Bull. S70.

Shanahan, G.J., Hart, R.J., 1966. Change in response of Lucilia cuprina Wied., to organophosphorus insecticides in Australia. Nature 212, 1466-1467.

Shapiro, E., Biezuner, T., Linnarsson, S., 2013. Single-cell sequencing-based technologies will revolutionize whole-organism science. Nat. Rev. Genet. 14, 618-630.

Shaw T. Wool as a 'clean, green' fibre; the implications of pesticide residues in wool - a challenge for regulatory authorities, drug companies, wool processors, veterinarians and farmers. In: Allworth MB, editor. Fourth International Congress of Sheep Veterinarians. Queensland: Australian Sheep Veterinary Society; 1997. p. $98-105$.

Sherman, R.A., 2009. Maggot therapy takes us back to the future of wound care: new and improved maggot therapy for the 21st century. J. Diabetes Sci. Technol. 3, 336-344.

Sigoillot, F.D., King, R.W., 2011. Vigilance and validation: keys to success in RNAi screening. ACS Chem. Biol. 6, 47-60.

Silver, K.S., Song, W., Nomura, Y., Salgado, V.L., Dong, K., 2010. Mechanism of action of sodium channel blocker insecticides (SCBIs) on insect sodium channels. Pestic. Biochem. Physiol. 97, 87-92.

Singh, B., Crippen, T.L., Zheng, L., Fields, A.T., Yu, Z., Ma, Q., et al., 2015. A metagenomic assessment of the bacteria associated with Lucilia sericata and Lucilia cuprina (Diptera: Calliphoridae). Appl. Microbiol. Biotechnol. 99, 869-883.

Skelly, P.J., Howells, A.J., 1987. The humoral response of sheep to antigens from larvae of the sheep blowfly (Lucilia cuprina). Int. J. Parasitol. 17, 1081-1087.

Soto-Adames, F.N., Robertson, H.M., Berlocher, S.H., 1994. Phylogenetic utility of partial DNA sequences of G6pdh at different taxonomic levels in Hexapoda with emphasis on Diptera. Ann. Entomol. Soc. Am. 87, 723-736.

Smith, D.H., Safari, E., Brien, F.D., Jaensch, K.S., Grimsom, R.J., 2009a. The relationship between crutch cover and production and easy care traits in Merino sheep. Proc. Assoc. Advmt. Anim. Breed. Genet. 18, 338-341.

Smith, J.L., Coldiz, I.G., Piper, L.R., Sandeman, R.M., Dominik, S., 2009b. Genetic resistance to growth of Lucilia cuprina larvae in Merino sheep. Aust. J. Exp. Agric. 48, 1210-1219.

Smith, W.J.M., Li, Y., Ingham, A., Collis, E., McWilliam, S.M., Dixon, T.J., et al., 2010. A genomics-informed, SNP association study reveals FBLN1 and FABP4 as contributing to resistance to fleece rot in Australian Merino sheep. BMC Vet. Res. 6, 27.

Smyth, K.A., Parker, A.G., Yen, J.L., McKenzie, J.A., 1992. Selection of dieldrin-resistant strains of Lucilia cuprina (Diptera: Calliphoridae) after ethyl methanesulfonate mutagenesis of a susceptible strain. J. Econ. Entomol. 85, 352-358.

Spradbery, J.P., 1991. A manual for the diagnosis of screw-worm fly. CSIRO Division of Entomology, ISBN 0643-05227-5, Canberra, ACT, Australia.

Stegle, O., Teichmann, S.A., Marioni, J.C., 2015. Computational and analytical challenges in single-cell transcriptomics. Nat. Rev. Genet. 16, 133-145.

Stevens, J.R., 2003. The evolution of myiasis in blowflies (Calliphoridae). Int. J. Parasitol. 33, 1105-1113.

Stevens, J., Wall, R., 1996. Classification of the genus Lucilia (Diptera: Calliphoridae): a preliminary parsimony analysis. J. Nat. Hist. 30, 1087-1094.

Stevens, J., Wall, R., 1997. Genetic variation in populations of the blowflies Lucilia cuprina and Lucilia sericata (Diptera: Calliphoridae). Random amplified polymorphic DNA analysis and mitochondrial DNA sequences. Biochem. System. Ecol. 25, 81-97.

St Johnston, D., 2013. Using mutants, knockdowns, and transgenesis to investigate gene function in Drosophila. Wiley Interdiscip. Rev. Dev. Biol. 2, 587-613.

Sung, P.J., Rodrigues, A.B., Kleinberger, A., Quatela, S., Bach, E.A., Philips, M.R., 2010. Cystolic Ras supports eye development in Drosophila. Mol. Cell. Biol. 30, 5649-5657.

Sze, S.H., Dunham, J.P., Carey, B., Chang, P.L., Li, F., Edman, R.M., et al., 2012. A de novo transcriptome assembly of Lucilia sericata (Diptera: Calliphoridae) with predicted alternative splices, single nucleotide 
polymorphisms and transcript expression estimates. Insect Mol. Biol. 21, 205-221.

Sze, S.H., Tarone, A.M., 2014. A memory-efficient algorithm to obtain splicing graphs and de novo expression estimates from de Bruijn graphs of RNA-Seq data. BMC Genomics 15, S6.

Tachibana, S., Numata, H., Goto, S.G., 2005. Gene expression of heat-shock proteins (Hsp23, Hsp70 and Hsp90) during and after larval diapause in the blow fly Lucilia sericata. J. Insect Physiol. 51, 641-647.

Tang, B., Wang, Y., Zhu, J., Zhao, W., 2015. Web resources for model organism studies. Genomics Proteomics Bioinformatics 13, 64-68.

Tarone, A.M., Foran, D.R., 2011. Gene expression during blow fly development: improving the precision of age estimates in forensic entomology. J. Forensic Sci. 56, S1.

Tellam, R.L., Bowles, V.M., 1997. Control of blowfly strike in sheep: current strategies and future prospects. Int. J. Parasitol. 27, 261-273.

Tellam, R.L., Eisemann, C.H., 1998. Inhibition of growth of Lucilia cuprina larvae using serum from sheep vaccinated with first-instar larval antigens. Int. J. Parasitol. 28, 439-450.

Tellam, R.L., Eisemann, C.H., Pearson, R.D., 1994. Vaccination of sheep with purified serine proteases from the secretory and excretory material of Lucilia cuprina larvae. Int. J. Parasitol. 24, 757-764.

Tellam, R.L., Eisemann, C.H., Vuocolo, T., Casu, R., Jarmey, J., Bowles, V., et al., 2001. Role of oligosaccharides in the immune response of sheep vaccinated with Lucilia cuprina larval glycoprotein, peritrophin-95. Int. J. Parasitol. 31, 798-809.

Tellam, R.L., Vuocolo, T., Eisemann, C., Briscoe, S., Riding, G., Elvin, C. et al., 2003. Identification of an immuno-protective mucin-like protein, peritrophin-55, from the peritrophic matrix of Lucilia cuprina larvae. Insect Biochem. Mol. Biol. 33, 239-252.

Tellam, R.L., Vuocolo, T., Johnson, S.E., Jarmey, J., Pearson, R.D., 2000. Insect chitin synthase cDNA sequence, gene organization and expression. Eur. J. Biochem. 267, 6025-6043.

Terras, M.A., Rose, H.A., Hughes, P.B., 1983. Aldrin epoxidase activity in larvae of a susceptible and a resistant strain of the sheep blowfly, Lucilia cuprina (Wiedeman). J. Aust. Entomol. Soc. 22, 256.

Thompson, C.R., Brogan, R.S., Scheifele, L.Z., Rivers, D.B., 2013. Bacterial interactions with necrophagous flies. Ann. Entomol. Soc. Am. 106, 799-809.

Tobe, S.S., Langley, P.A., 1978. Reproductive physiology of Glossina. Annu. Rev. Entomol. 23, 283-307.

Tomberlin, J.K., Crippen, T.L., Tarone, A.M., Singh, B., Adams, K., Rezenom, Y.H., et al., 2012. Interkingdom responses of flies to bacteria mediated by fly physiology and bacterial quorum sensing. Anim. Behav. 84, 1449-1456.

Tourle, R., Downie, D.A., Villet, M.H., 2009. Flies in the ointment: a morphological and molecular comparison of Lucilia cuprina and Lucilia sericata (Diptera: Calliphoridae) in South Africa. Med. Vet. Entomol. 23, 614.

Turner, H.N., Hayman, R.H., Riches, J.H., Roberts, N.F., Wilson, L.T., 1953. Physical definition of sheep and their fleece for breeding and husbandry studies, with particular reference to merino sheep. Div. Anim. Hlth. \& Prodn. Report No. 4, (Series SW-2), C.S.I.R.O., Australia.

Ujváry, I., Casida, J.E., 1997. Partial synthesis of 3-0-vanilloylveracevine, an insecticidal alkaloid from Schoenocaulon officinale. Phytochem. 44, 1257-1260.

Ullerich, F.-H., Schöttke, M., 2006. Karyotypes, constituitive heterochromatin, and genomic DNA values in the blowfly genera Chrysomya, Lucilia, and Protophormia (Diptera: Calliphoridae). Genome 49, 584-597.

Urech, R., Green, P.E., Rice, M.J., Brown, G.W., Webb, P., Jordan, D., et al., 2009. Suppression of populations of Australian sheep blowfly, Lucilia cuprina (Wiedemann) (Diptera: Calliphoridae), with a novel blowfly trap. Aus. J. Entomol. 48, 182-188.

Venken, K.J.T., Bellen, H.J., 2014. Chemical mutagens, transposons and transgenes to interrogate gene function in Drosophila melanogaster. Methods 68, 15-28.

Venken, K.J.T., Sarrion-Perdigones, A., Vandeventer, P.J., Abel, N.S., Christiansen, A.E., Hoffman, K.L., 2015. Genome engineering: Drosophila melanogaster and beyond. WIREs Dev. Biol. doi: 10.1002/wdev.214.

Wall, R., 2012. Ovine cutaneous myiasis: effects on production and control. Vet. Parasitol. 189, 44-51.

Wall, R., Fisher, P., 2001. Visual and olfactory cue interaction in resource-location by the blowfly, Lucilia sericata. Physiol. Entomol. 26, 212-218.

Waterhouse, D.F., 1947. The relative importance of live sheep and of carrion as breeding grounds for the Australian sheep blowfly Lucilia cuprina. Bull. Coun. Sci. Industr. Res. Aust. no. 217.

Waterhouse, D.F., Paramonov, S.J., 1950. The status of the two species of Lucilia (Diptera, Calliphoridae) attacking sheep in Australia. Aust. J. Sci. Res. B3, 310- 336. 
Watts, J.E., Murray, M.D., Graham, N.P., 1979. The blowfly strike problem of sheep in New South Wales. Aust. Vet. J. 55, 325-334.

Wei, T., Ishida, R., Miyanaga, K., Tanji, Y., 2014. Seasonal variations in bacterial communities and antibioticresistant strains associated with green bottle flies (Diptera: Calliphoridae). Appl. Microbiol. Biotechnol. 98, 4197-4208.

Whitten, M.J., Dearn, J.M., McKenzie, J.A., 1980. Field studies on insecticide resistance in the Australian sheep blowfly, Lucilia cuprina. Aust. J. Biol. Sci. 33, 725-735.

Wiedenheft, B., Sternberg, S.H., Doudna, J.A., 2012. RNA-guided genetic silencing systems in bacteria and archaea. Nature 482, 331-338.

Willadsen, P., 1997. Novel vaccines for ectoparasites. Vet. Parasitol. 71, 209-222.

Williams, K.A., Villet, M.H., 2014. Morphological identification of Lucilia sericata, Lucilia cuprina and their hybrids (Diptera, Calliphoridae). Zookeys 420, 69-85.

Wissler, L., Gadau, J., Simola, D.F., Helmkampf, M., Bornberg-Bauer, E., 2013. Mechanisms and dynamics of orphan gene emergence in insect genomes. Genome Biol. Evol. 5, 439-455.

Wynant, N., Santos, D., Broeck, J. V., 2014. Biological mechanisms determining the success of RNA interference in insects. Int. Rev. Cell Mol. Biol. 312, 139-167.

Xu, J., Ren, X., Sun, J., Wang, X., Qiao, H.H., Xu, B.W., et al., 2015. A toolkit of CRISPR-based genome editing systems in Drosophila. J. Genet. Genomics. 42, 141-149.

Yamamoto-Hino, M., Goto, S., 2013. In vivo RNAi-based screens: studies in model organisms. Genes (Basel) 4, 646-665.

Yan, Y., Scott, M. J., 2015. A transgenic embryonic sexing system for the Australian sheep blow fly Lucilia cuprina. Sci. Rep. 5, 16090.

Young, A.R., Mancuso, N., Bowles, V.M., 1999. Biochemical aspects of egg hatch in endo- and ectoparasites: potential for rational drug design. Int. J. Parasitol. 29, 861-867.

Young, A.R., Meeusen, E.N.T., Bowles, V.M., 1996. Characterization of ES products involved in wound initiation by Lucilia cuprina larvae. Int. J. Parasitol. 26, 245-252.

Young, N.D., Chan, K.-G., Korhonen, P.K., Chong, T.M., Ee Han Jen, R., Mohandas, N., et al., 2015. Exploring molecular variation in Schistosoma japonicum in China. Sci. Rep. 5, 17345.

Yu, N., Christiaens, O., Liu, J., Niu, J., Cappelle, K., Caccia, S., et al., 2013. Delivery of dsRNA for RNAi in insects: an overview and future directions. Insect Sci. 20, 4-14.

Zhang, H., Li, H.C., Miao, X.X., 2013. Feasibility, limitation and possible solutions of RNAi-based technology for insect pest control. Insect Sci. 20, 15-30.

Zhong, W., Sternberg, P.W., 2006. Genome-wide prediction of C. elegans genetic interactions. Science 311, 1481-1484. 
Table 1 | Features of the draft genome of Lucilia cuprina

\begin{tabular}{|c|c|}
\hline \multicolumn{2}{|l|}{ Description } \\
\hline Total number of base pairs within assembled scaffolds & $458,190,778$ \\
\hline Total number of scaffolds; contigs & 4,$436 ; 74,043$ \\
\hline N50 length in bp; total number $>$ N50 in length & 744,$413 ; 165$ \\
\hline N90 length in bp; total number > N90 in length & 126,$471 ; 736$ \\
\hline CEGMA results (complete; partial) & $96.0 \% ; 100.0 \%$ \\
\hline GC content of the whole genome $(\%)$ & 29.3 \\
\hline Number of putative coding genes & 14,554 \\
\hline Transcription factors ${ }^{\mathrm{a}, \mathrm{b}}$ & 446 \\
\hline Transporters $^{\mathrm{a}, \mathrm{b}}$ & 367 \\
\hline Peptidases $^{\mathrm{a}, \mathrm{b}}$ & 260 \\
\hline Excretory/secretory (ES) proteins $s^{\mathrm{a}, \mathrm{b}}$ & 234 \\
\hline Phosphatases ${ }^{\mathrm{a}, \mathrm{b}}$ & 199 \\
\hline G protein-coupled receptors (GPCRs) & 197 \\
\hline Kinases $^{\mathrm{a}, \mathrm{b}}$ & 167 \\
\hline Ion channel proteins $s^{\mathrm{a}, \mathrm{b}}$ & 136 \\
\hline GTPases $^{\mathrm{a}, \mathrm{b}}$ & 92 \\
\hline
\end{tabular}

${ }^{a}$ Numbers predicted based on gene support in $>2$ publicly available datasets.

${ }^{\mathrm{b}}$ Some predicted proteins belong to multiple categories.

Table 2 | Insecticide resistance genes

\begin{tabular}{lll}
\hline \hline Gene & Insecticide & Additional details \\
\hline $\boldsymbol{A c e}$ (acetylcholinesterase) & organophosphorus resistance & \\
\hline $\boldsymbol{R} \boldsymbol{d l}$ (resistance to dieldrin) & dieldrin resistance & \\
\hline $\boldsymbol{L} \boldsymbol{c a E 7}$ (or $\boldsymbol{R o p} 1)$ & organophosphorus resistance & encodes carboxylesterase E3 \\
\hline $\boldsymbol{S c l}$ & organophosphorus resistance & $\begin{array}{l}\text { transmembrane receptor for } \\
\text { intracellular signaling; proposed } \\
\text { to be the Modifier of phenotypes } \\
\text { associated with Rop1-mediated } \\
\text { organophosphorus resistance }\end{array}$ \\
\hline
\end{tabular}

Lc $\alpha 6$ (nicotinic acetylcholine spinosad resistance

receptor $\alpha 6$ subunit) 